

Curso de especialização em Turismo e Desenvolvimento Sustentável

\title{
IMPACTOS DA VISITAÇÃO TURÍSTICA SOBRE ANIMAIS EM ÁREAS NATURAIS
}

Danilo Gustavo Rodrigues de Oliveira

Rogério Ferreira de Souza Dias (especialista)

Brasília, 2007 


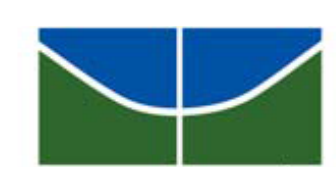

UNIVERSIDADE DE BRASÍLIA

Centro de Excelência em Turismo

Pós-graduação Lato sensu

Curso de especialização em Turismo e Desenvolvimento Sustentável

\title{
IMPACTOS DA VISITAÇÃO TURÍSTICA \\ SOBRE ANIMAIS EM ÁREAS NATURAIS
}

\author{
Danilo Gustavo Rodrigues de Oliveira \\ Orientador: Prof. Rogério Ferreira de Souza Dias (especialista)
}

Monografia apresentada ao Centro de Excelência em

Turismo - CET da Universidade de Brasília - UnB como

requisito parcial à obtenção do grau de especialista em

Turismo e Desenvolvimento Sustentável

Brasília, 2007 
Oliveira, Danilo Gustavo Rodrigues de

Impactos da visitação turística sobre animais em áreas naturais/

Danilo Gustavo R. de Oliveira. - Brasília, 2007

viii, $69 \mathrm{f}$. : il.

Monografia (especialização) - Universidade de Brasília, Centro de Excelência em Turismo, 2007.

Orientador: Rogério Ferreira de Souza Dias.

1. Turismo. 2. impactos ambientais. 3. fauna silvestre. I. Título. 




\title{
UNIVERSIDADE DE BRASÍLIA
}

Centro de Excelência em Turismo

\section{Pós-graduação Lato sensu}

\section{Curso de especialização em Turismo e Desenvolvimento Sustentável}

\author{
Danilo Gustavo R. de Oliveira
}

Aprovado por:

Prof.: Rogério Ferreira de Souza Dias

Prof $^{a}$. Dra. Iara Lúcia Gomes Brasileiro

Prof. Dr. Umberto Euzébio 


\section{AGRADECIMENTOS}

Agradeço primeiramente a Deus, sem o qual nada disso seria possível e a quem sempre pude recorrer quando em desespero.

À minha família, que me incentivou a fazer esse curso desde o início. À minha mãe, que não me permitiu desistir da inscrição do curso e foi minha companheira de especialização. À minha instituição de fomento à pesquisa, meu pai, que me possibilitou a realização desse curso.

À Thaís que esteve sempre ao meu lado me dando apoio, amor e conselhos. Agradeço todos os dias por você estar presente em minha vida e me dar sempre forças novas para seguir em frente.

Ao professor Rogério Dias, meu orientador e amigo, pelos valiosos conselhos e correções feitas aos manuscritos iniciais. Obrigado por me incentivar a fazer uma pesquisa interessante mesmo depois de problemas encontrados e mudanças de tema seguidas.

Aos colegas de curso, pelas horas de diversão e protestos juntos durante o intervalo. Sempre foram de grande valia as nossas terapias semanais para avaliar a tensão.

À coordenadora do curso prof ${ }^{\mathrm{a}}$. Iara pela abertura desse oportunidade para nós. Que nossas reivindicações não sejam esquecidas em próximas realizações.

Aos meus grandes amigos Hernani e Thiago, que estiveram sempre comigo em todos os momentos de diversão, descoberta e dificuldade.

À todos que me ajudaram nessa caminhada de qualquer maneira, valeu pelo apoio e incentivo. 


\section{RESUMO}

A atividade de turismo de vida silvestre, por se realizar em áreas naturais e buscar animais não domesticados, possui potencial de perturbar a dinâmica do ecossistema visitado. O objetivo do trabalho foi levantar impactos provenientes dessa prática no mundo e no Brasil. As atividades turísticas em meio aquático e terrestre foram divididas nesse estudo por suas diferenças em relação aos impactos apresentados e características do ambiente. Também as atividades ocorridas no Brasil foram diferenciadas visando maior ênfase na forma de desenvolvimento desse turismo no nosso país. Foram enviadas mensagens de correioeletrônico para instituições que trabalham com conservação de espécies e turismo no Brasil visando entender as características e impactos do turismo nessas localidades. Em ambiente terrestre, os impactos causados pelo turismo incluem: mudança de padrões comportamentais (afastamento do território, alteração na taxa de forrageamento e vigilância, rompimento da ligação par-filhote, aumento da agressividade e habituação), distúrbio do balanço ecológico, transmissão de doenças, morte de animais e impactos mais indiretos. A alimentação artificial pode tornar esses impactos mais suscetíveis. Em ambiente marinho, os impactos mais comuns em cetáceos incluem: mudanças no padrão de mergulhos, velocidade de natação e orientação, dispersão do grupo, orçamento de atividades, eventos comportamentais e padrão de distribuição e uso do habitat. Recifes são destruídos e perdem em beleza cênica e biodiversidade e outros animais podem sofrer com engasgamentos e até a completa extinção (foca monge). No Brasil, principalmente as atividades de observação de cetáceos e mergulho são populares, mas nosso país tem potencial ainda para desenvolver essa atividade devido à grande biodiversidade existente.

Palavras-chave: Turismo, impactos ambientais, fauna silvestre 


\begin{abstract}
Wildlife tourism activity, for occurring in natural areas and in search for undomesticated animals, has the potential to disturb the dynamics of the visited ecosystem. The objective of this work was to raise the impacts from this activity in the world and in Brazil. Tourism in the aquatic and terrestrial environments were divided in this study for their differences in relation to presented impacts and characteristics of the environment. Also the brazilian activities were separated looking for greater emphasis in the way of development of this tourism in our country. E-mail messages were sent to institutions that work with conservation of species and tourism in Brazil as a way to understand the tourism and its impacts in those places. In terrestrial environments, the impacts caused by tourism includes: change in behavioral patterns (distancing of territory, change in foraging rates and vigilance, break of mother-offspring bond, increase in aggressiveness and habituation), disturb in ecological balance, transmission of diseases, death of animals and more indirect impacts. Artificial feeding can make these impacts more susceptible. In marine environment the more common impacts in cetaceans includes: changes in dive pattern, swim speed, course and orientation, group dispersion, activity budget, behavioral events and distribution patterns and habitat use. Reefs are destroyed and loose scenic beauty and biodiversity and other animals can suffer with choking and even extinction (monk seal). In Brazil, mainly the activities of whale watching and diving are popular, but our country still have potential to develop a lot this activity due to the great biodiversity present.
\end{abstract}

Keywords: tourism, environmental impacts, wildlife 


\section{SUMÁRIO}

Agradecimentos

Sumário

viii

Introdução

Objetivos

4

Material e Métodos

Capítulo 1 - Interações turísticas com animais terrestres $\quad 6$

1.1 - Alimentação artificial $\quad 7$

1.2 - Impactos diretos 10

1.2.1 Mudança de padrões comportamentais naturais $\quad 12$

1.2.2 Distúrbio do balanço ecológico 15

1.2.3 Saúde/ doenças 16

1.2.4 Morte de animais individuais 17

$\begin{array}{ll}1.3 \text { - Impactos indiretos } & 19\end{array}$

1.4 - Redução de efeitos $\quad 21$

Capítulo 2 - Interações com animais aquáticos $\quad 24$

2.1 - Embarcações 24

2.1.1 - Interações sonoras $\quad 29$

2.1.2 - Encontros na água $\quad 31$

2.2 - Interações em terra 34

2.3 - Golfinhos solitários sociáveis $\quad 37$

Capítulo 3 - Situações e perspectivas brasileiras $\quad 40$

3.2 - Safári $\quad 41$

3.2.1 - Observação de primatas $\quad 42$

3.2.2 - Outros mamíferos 46

3.3 - Turismo de observação da vida aquática $\quad 47$

3.3.1 - Turismo de observação de cetáceos 47

3.3.2 - Turismo de mergulho e de ambientes recifais $\quad 50$

3.4 - Observação de aves $\quad 52$

3.5 - Caça e pesca esportiva $\quad 54$

$\begin{array}{ll}3.6 \text { - Sugestões } & 55\end{array}$

Considerações finais $\quad 58$

$\begin{array}{ll}\text { Comunicações pessoais } & 60\end{array}$

$\begin{array}{ll}\text { Referências bibliográficas } & 60\end{array}$ 


\section{INTRODUÇÃO}

A atividade turística em áreas naturais tem crescido com velocidade assustadora nos últimos anos. O crescente foco no meio ambiente como uma forma de fuga de áreas urbanas estressantes e movimentadas e como preocupação global com o futuro do planeta são os motivos dessa grande demanda. Como, em geral, se assume que visitantes de áreas naturais são ecologicamente conscientes e preocupados com a conservação dos recursos naturais e culturais do local, pouca atenção tem sido prestada aos impactos causados por essa visitação.

Essa atividade ecológica e socialmente correta não se aplica a todas as formas de turismo em área natural, e sim a uma forma específica conhecida como ecoturismo. A partir da definição do termo ecoturismo surge uma dificuldade devido à grande variabilidade nas definições apresentadas conforme o autor. Orams (1995) discute que há um espectro de definições que variam do tudo em ambiente natural é ecoturismo ao é impossível se fazer ecoturismo.. Efeito semelhante ocorre com o termo “desenvolvimento sustentável”, o qual por ser mais utilizado e discutido acabou virtualmente sem utilidade prática devido à profusão de conceitos diferentes. Uma lista de algumas definições de ecoturismo se encontra no quadro 1.

\section{Quadro 1- Definições de ecoturismo}

Numerosas definições de ecoturismo existem em uso:

"Visitas a parques nacionais e outras áreas naturais com foco em visualizar e aproveitar plantas e animais assim como qualquer cultura indígena” (Boo 1990)

"Uma experiência de viagem iluminadora que contribui para a conservação do ecossistema enquanto respeita a integridade de comunidade hospedeira” (Catter \& Lowman 1994) 
"Viagens responsáveis para áreas naturais que conservam o meio ambiente e aumentam o bem estar das populações locais” (Lindberg \& Hawkins 1993)

“Turismo que envolve viagens para áreas naturais relativamente não perturbadas e não contaminadas com o objeto específico de estudo, admiração e aproveitamento da paisagem e de suas plantas e animais selvagens assim como qualquer aspecto cultural (do passado ou do presente) enontrado nessas áreas” (Ceballos-Lascurain 1993)

“Turismo que é baseado em ambientes naturais relativamente não perturbados, não é degradante, é sujeito de um regime de gestão adequada e é um contribuinte direto para a proteção contínua e gestão das áreas protegidas usadas” (Valentine 1991)

“Turismo que é ambientalmente sensível” (Muloin 1991)

"Viagens intecionais que criam um entendimento da história cultural e natural, enquanto salvaguarda a integridade do ecossistema e produz benefícios econômicos que encorajam a conservação” (Ryel \& Grasse 1991)

"Turismo natural de baixo impacto que contribui para a manutenção de espécies e habitats tanto diretamente através da contribuição para a conservação e/ou indiretamente providenciando renda suficiente para a comunidade local para as pessoas valorizarem, e portanto proteger, sua herança de área natural como uma forma de renda” (Goodwin 1996) "Ecoturismo é um segmento da atividade turística que utiliza, de forma sustentável, o patrimônio natural e cultural, incentiva sua conservação e busca a formação de uma consciência ambientalista através da interpretação do ambiente, promovendo o bem-estar das populações” (EMBRATUR, 2006)

Fonte: adaptado de Roe et al (1997)

Os conceitos utilizados, apesar de bastante diversos, parecem sempre tocar no ponto de que o ecoturismo ocorre em áreas naturais e possui um desejo de minimizar os impactos negativos (Orams, 1995). Alguns outros conceitos incluem também como fator importante o envolvimento da comunidade local e seu interesse em também conservar a natureza.

Devido à maior apreciação da mídia internacional pelo ecoturismo ao invés do turismo convencional uma grande quantidade de operadoras de turismo surgiu com o título 
de ecoturismo e sem nenhuma certificação se as atividades desenvolvidas eram realmente pouco impactantes e ajudavam a conservar os recursos naturais. Existe um senso comum de que as atividades ecoturísticas são pouco impactantes por causa do nível de consciência ambiental dos participantes e do pequeno número. No entanto, poucos estudos comprovam baixa perturbação por parte dos ecoturistas, ao contrário alguns afirmam que a atividade é mais prejudicial por se dar em ambientes isolados e frágeis que são mais prováveis de sofrer com as perturbações (YHA 1996; apud Roe et al, 1997)

Trataremos nesta monografia dos impactos do turismo de vida selvagem (do termo original "wildlife tourism”) que é um dos segmentos do turismo em áreas naturais e engloba o ecoturismo (não pretendemos criar um novo segmento do turismo e sim facilitar a compreensão das atividades). Turismo de vida selvagem inclui uma grande quantidade de atividades, como: observação de aves e de cetáceos (baleias e golfinhos), visualização de vida selvagem, safáris, mergulhos em recifes de coral, caça e pesca esportiva. Consideramos como turismo de vida selvagem toda e qualquer atividade turística que interaja com animais selvagens em ambiente natural com finalidade recreativa. Lemelin e Smale (2005) criaram uma classificação dos turistas de áreas naturais com 5 categorias e dentro destas apenas a $4^{\mathrm{a}}$ e a $5^{\mathrm{a}}$, correspondente a 36,5\% dos turistas da área Churchill de gestão da vida selvagem no Canadá, são considerados ecoturistas. Para não denominar de ecoturismo atividades sem intenção de minimizar impactos e ajudar comunidades locais ou turistas que se classifiquem nas categorias de 1 a3 foi preferível utilizar o termo mais abrangente.

Nos últimos anos essa atividade passou por uma mudança nas áreas mais visitadas especialmente para países em desenvolvimento ricos em biodiversidade, principalmente: América Central, Amazônia, Sul e Leste da África, Sul e Sudeste da Ásia (BMZ, 1995 in 
Roe et al, 1997). O Brasil então tem potencial para ocupar o primeiro lugar em número de atividades de turismo de vida selvagem por ser o país com a maior biodiversidade do mundo, possuindo 1/5 de toda a vida do planeta. Pesquisa sobre os impactos das atividades, portanto, devem ser feitas antes do fluxo de visitantes começar para assegurar a sustentabilidade do projeto.

Não pretendemos aqui fazer uma revisão de todos os impactos em vida selvagem já documentados em todas as classes de animais, trata-se de um levantamento bibliográfico sobre os principais impactos advindos do turismo em animais no mundo para depois focalizar a questão para o caso brasileiro e apontar deficiências ou eficiências e caminhos a seguir.

\section{OBJETIVOS}

- Apontar os principais tipos de impactos que surgem de diferentes atividades do turismo de vida selvagem no mundo;

- Relatar no caso brasileiro deficiências e eficiências no turismo nacional e possíveis rumos a seguir.

\section{MATERIAL E MÉTODOS}

Foi utilizada pesquisa bibliográfica para levantar todos os dados apresentados na literatura sobre os impactos do turismo de vida selvagem sobre animais terrestres e aquáticos mundiais e todas as interações brasileiras encontradas.

Além disso, um questionário simplificado foi enviado por correio eletrônico às instituições brasileiras que trabalham com a conservação de espécies e turismo com as seguintes perguntas: 
- Há algum caso de animais que saíram machucados durante as visitas turísticas?

- Há casos de turistas machucados ou doentes por causa da interação?

- Os turistas podem alimentar os animais?

- Existe a presença de guias durante as interações?

- Os animais mudam seu comportamento em decorrência desse contato?

- Existe alguma publicação que analise essa interação?

Desses questionários enviados quatro foram devidamente respondidos e incluídos na discussão dos casos nacionais. A descrição e discussão dos questionários submetidos encontram-se no capítulo 3 no tópico referente ao tipo de turismo trabalhado pela instituição. 


\section{Capítulo 1 \\ INTERACÕ̃ES TURÍSTICAS COM ANIMAIS TERRESTRES}

As atividades de turismo voltadas para áreas naturais têm o potencial para causar diversos impactos na vida selvagem devido à grande aproximação das pessoas com os animais, a provisão de alimentos, a transmissão de doenças aos dois lados da interação, mudanças de comportamento essenciais ao animal e morte de alguns indivíduos (Roe et al, 1997). Pouca atenção tem sido prestada na pesquisa dos impactos advindos dessa interação, principalmente por parte dos países em desenvolvimento, em parte devido à suposição que atividades "ecoturísticas” são ambientalmente consciente e culturalmente responsável e, portanto, sustentáveis.

Animais terrestres foram separados dos aquáticos nesse trabalho já que o tipo de relacionamento que empreendemos com os dois tipos de animais é diferente. Animais terrestres freqüentemente estão expostos à severa competição e/ou predação por nossa espécie de diversos modos além do turismo. Fatores que impactam as populações de animais terrestres silvestres incluem: tráfico de animais silvestres, caça, desmatamento, domesticação, biopirataria, introdução de espécies exóticas, doenças e turismo de forma que, na maioria das vezes, se torna complicado diferenciar a fonte da perturbação. Essas fontes, apesar de presentes, são reduzidas no meio aquático tornando o impacto do turismo mais fácil de ser acessado. Outro critério que influi na decisão da separação foi a simples diferença nas características do meio ambiente e de estilos de vida entre os animais. 
Nesse capítulo são citados trabalhos existentes na literatura sobre os principais impactos da visitação decorrentes das atividades de safári, caça esportiva, observação de aves e de outros animais selvagens, após fazer uma discussão sobre um fator que pode agravar efeitos na vida animal, a alimentação artificial. Ao final são apresentadas alternativas de gestão mais ecológicas para um turismo mais responsável em ambiente natural.

\section{1 - ALIMENTAÇÃO ARTIFICIAL}

É comum em várias partes do mundo a utilização de alimentos para a aproximação e melhor visualização de animais silvestres ou por guias turísticos que pretendem proporcionar uma melhora na qualidade do passeio aos visitantes. Apesar de não ser exatamente um impacto negativo e, para algumas espécies, ser benéfico e ajudar na conservação, alimentação de animais selvagens potencializa o surgimento de vários impactos. É importante ressaltar que essa prática não deve ser vista como totalmente negativa, ela pode resultar em benefícios de ordem econômica, psicológica, social e ambiental aos turistas e às comunidades locais envolvidas com a área visitada (Orams, 2002) e também auxiliar na conservação da espécie.

Disponibilidade de alimento é considerado o fator mais importante na determinação do orçamento de atividade diária de um animal, ou seja, o tempo alocado para cada atividade (Orams, 2002; Baldellou \& Adan, 1997). Portanto, a alimentação de animais tem a capacidade de alterar padrões comportamentais naturais, tamanho e densidade populacional. De fato, suplementos alimentares fornecidos por turistas tipicamente fazem com que os animais passem menos tempo forrageando e caçando e mais tempo descansando, socializando ou caminhando. (Saj et al, 1999). Outros padrões 
comportamentais alterados incluem: aumento na atividade procriativa, tamanho do grupo, densidade populacional (Zhao, 1999) e interrupção de padrões migratórios naturais (revisão em Orams, 2002). Também o balanço ecológico da comunidade pode ser alterado aumentando a pressão de predação sobre as presas ou o número de competidores no local (Ramon et al, 1996 apud Orams, 2002), assim como pode manipular a reprodução atrasando ou adiantado a época de nascimentos de filhotes (Boutin, 1990 apud Orams, 2002).

Nem sempre a mudança no orçamento diário de atividade do animal é uma coisa ruim, já que esta atividade é largamente utilizada em unidades que visam à conservação animal, como os zoológicos, na tentativa de aumentar o tamanho populacional de espécies ameaçadas de extinção. Dependendo do grupo animal analisado a alimentação artificial de espécimes silvestres é até estimulada. Um bom exemplo disso é o caso das aves em que grandes instituições ornitológicas ${ }^{1}$, como a Aliança Britânica para Ornitologia (BTO), a sociedade real para a proteção das aves (RSPB) e o laboratório Cornell para Ornitologia, entre outras instituições encorajam as pessoas a alimentar aves e até ensinam nos sites como fazer (BTO, 2006; O’Leary \& Jones, 2006).

Após muito tempo desta prática em um local ela pode tornar os animais envolvidos dependentes de alimentação provida por humanos e causar a perda da capacidade de forragear atrás de comida natural. Quando isso acontece, a retirada do aprovisionamento artificial pode acarretar na morte por fome de alguns animais e os filhotes criados por esses indivíduos provavelmente não aprenderão as habilidades cruciais para se alimentar sozinhos. Além disso, os animais se tornam habituados ao contato com o homem, o que os

\footnotetext{
${ }^{1}$ Ornitologia é a ciência que estuda as aves.
} 
torna mais expostos à influência humana e, consequentemente, mais suscetíveis a serem machucados, atropelados, montados, baleados ou agarrados por pessoas (Shackley, 1996 apud Orams, 2002).

Animais aprovisionados também aumentam seu nível de agressão a fim de obter uma maior quantidade de alimentos dos turistas e, freqüentemente roubam lanche de visitantes. Esse comportamento é típico de primatas em áreas naturais (por exemplo, macacos prego Mendes et al, 2004; Pinha et al, 2004;), mas espécies de ursos, cangurus, cachorros, guaxinim, quati, gambá, leões marinhos, golfinhos, peixes e até aves já foram relatadas exibindo maiores níveis de agressão provavelmente devido ao aprovisionamento (Orams, 2002).

A alimentação artificial também pode interferir na saúde do animal de diversas formas, no entanto a dificuldade de demonstrar causa e efeito na saúde de animais silvestres torna o número de pesquisas que comprovem esses efeitos muito pequeno. Seja transmitindo doenças antrópicas ou ferindo diretamente um indivíduo esse fator talvez seja o que mais preocupa as autoridades responsáveis pela gestão das áreas naturais. Talvez por isso o Parque Nacional de Victoria na Austrália exibia a seguinte informação sobre cangurus:

”Pão, bife, salsicha e outras comidas são estranhas aos seus sistemas digestivos e causam problemas de saúde. Também, plástico, papel e outros materiais podem ficar presos nas gargantas deles, levando a infecções ou engasgos. Cangurus não são adaptados a comer comida humana processada. Isso causa problemas de saúde sérios e comumente resulta na morte precoce do animal” (Burger, 1997, p. 6. Tradução livre) 


\section{2 - IMPACTOS DIRETOS}

Com a incessante busca de atrações "grandes” no meio natural (animais de grande porte, outros animais em grande número ou em grande proximidade) (Newlands, 1997) a visualização de animais selvagens comumente transgride algumas barreiras éticas (figura 1). Os erros mais comuns desse tipo de turista são: muito cheiro, barulho e impaciência (Amodeo, 2004) o que fazem com que eles se tornem mais conspícuos e mais propícios a perturbar as populações visitadas.

É importante ressaltar que, embora praticamente qualquer ação humana percebida pelo animal gere uma reação mesmo que não perceptível, o efeito pode ser apenas de curto prazo ou em uma pequena parcela da população. Para o impacto ser realmente considerado significativo na população estudada é necessário que ele permaneça por um longo prazo e afete grande parte da amostra populacional. Dessa forma a reação não será apenas passageira, ela se torna constante e causa efeitos biologicamente importantes, como: diminuição do sucesso reprodutivo ${ }^{2}$ e do tamanho populacional. Estudos de longo prazo são raros e difíceis de se fazer devido ao tempo necessário para sua execução, portanto a maioria dos estudos aqui apresentados analisam somente efeitos de curto prazo

\footnotetext{
2. Sucesso reprodutivo é uma medida do número de descendentes férteis que um indivíduo consegue produzir durante toda a sua vida. Um indivíduo de alto sucesso reprodutivo consegue espalhar seus genes na população mais rapidamente e assim é favorecido por seleção natural.
} 


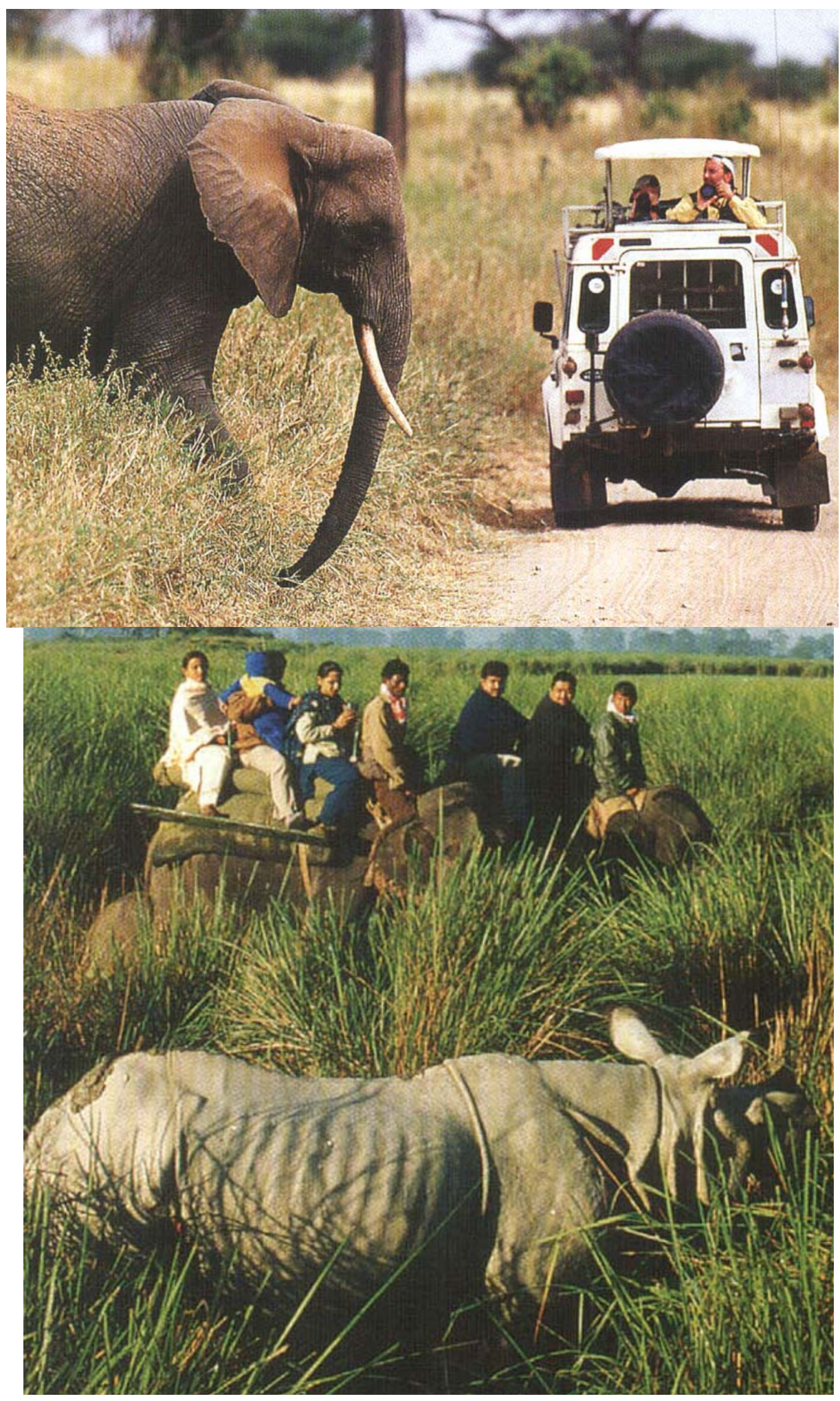

Figura 1. Exemplos de trangressões éticas na visitação turística. a) foto de John Lambert/ Alany e b) foto de Mike Powles 


\subsection{1 - Mudança de padrões comportamentais naturais}

Uma grande variedade de distúrbios pode ocorrer no comportamento de um animal em decorrência da atividade turística, como: afastamento do território, alteração na taxa de forrageamento e vigilância, rompimento da ligação par-filhote, aumento da agressividade e habituação.

Efeitos comportamentais são rapidamente percebidos quando carros de safári saem de suas trilhas naturais para perseguir chitas e proporcionar melhor experiência turística aos seus visitantes. As chitas no parque nacional de Ambroseli no Quênia demonstraram que evitavam ativamente os veículos de safári, atrasavam a caçada na presença de veículos e se tornaram mais crepuscular, perdendo sua característica diurna (Henry, 1980 in Roe et al, 1997). O aumento no número de visitantes no grupo, na altura do som que eles emitiam e aproximações diretas aos animais tornavam mais provável a ocorrência de distúrbios comportamentais (Burney, 1980 in Roe et al, 1997).

Grupos de ungulados $^{3}$ na África oriental são separados dos seus filhotes por causa da aproximação de veículos turísticos, o que pode afetar os laços de reconhecimento individuais tornando provável os pais abandonarem os filhotes, além de aumentar o risco de predação do jovem (Edington \& Edington, 1986 apud Roe et al, 1997).

Grupos de renas selvagens na Noruega evitam áreas próximas a resorts turísticos causando uma superexploração das áreas mais afastadas (Nellemann et al, 1999). Em uma área de 5 km de distância do resort praticamente nenhum animal foi visto, até $10 \mathrm{~km}$ de distância dele praticamente só machos adultos ocorreram e os outros animais ficaram

\footnotetext{
${ }^{3}$ Ungulados é uma superordem de mamíferos que corresponde a animais que andam sobre as unhas. Exemplos incluem: elefante, cavalos, antílope, antas e rinocerontes (Pough et al, 1999)
} 
distantes mais de $10 \mathrm{~km}$ do resort. Isso resultou em uma superexploração dos liquens ingeridos por eles causando redução da qualidade do recurso alimentar. Além disso, os animais foram impedidos de migrar para áreas mais produtivas no verão (como é comum nessa espécie) por causa da quantidade de estradas que fragmentam a rota de migração original (Nellemann et al, 1999).

Turistas foram observados perseguindo lontras em rios no parque nacional Manu no Peru perturbando sua alimentação, enquanto guias foram observados cavando ninhos de tartarugas, perseguindo lontras, onças e antas e perturbando aves com ninho na margem (Dunstone \& O’Sullivan, 1994 in Roe et al, 1997).

Em um sítio arqueológico de Belize macacos bugios (Alouatta pigra) são avistados incidentalmente na trilha para ruínas arqueológicas e o contato com turistas encorajou machos adultos a descer ao chão e a rugir para os turistas, algumas vezes morderam pessoas, roubaram sacos plásticos e até foram mordidos por um cachorro (Grossberg et al, 2003). As fêmeas e os jovens se afastam espalhando-se e subindo nas árvores na presença do grupo de visitantes e essa resposta aumenta com o aumento de pessoas no grupo. Esse comportamento quebra padrões normais de atividade e, conseqüentemente, grupos mais expostos ao turismo apresentam maior mortalidade infantil (Grossberg et al. 2003). Pesquisadores de primatas intencionalmente expõe grupos de macacos à presença humana para habituá-los e facilitar a interação, o que ocorre tanto para os cientistas quanto para os turistas (Blom et al, 2003).

Ursos polares passaram a ficar mais tempo na posição sentado e parado e menos na posição deitado na presença de veículos turísticos em Churchill no Canadá (Eckhardt, 2000). A velocidade de aproximação do veículo e ângulo de aproximação em relação ao 
caminho do urso são variáveis que influenciam na probabilidade de o urso responder ao estímulo.

Uma população de aves no refúgio de vida selvagem Loxahatchee na Flórida é intensamente exposta ao turismo em parte do ano e, durante o período em que as pessoas estão o total de tempo dedicado ao forrageamento, à vigilância e o número de bicadas diminuiu. As aves consistentemente fugiram da aproximação dos turistas e mudaram sua taxa de forrageamento à medida que o som aumentou (Burger \& Gochfeld, 1998).

Populações de andorinhões e de águias chilena e cinzenta na região da serra dos Pirineus em Pirenópolis-GO estão tendo os seus locais de nidificação destruídos devido à prática de rappel e escalada (Rogério Dias, comunicação pessoal). Essas atividades de turismo de aventura costumam utilizar paredões rochosos e áreas com quedas d’água, também comum para a nidificação de diversas aves.

Na verdade, a observação de aves é uma atividade que é encarada como totalmente sustentável, porém impactos devido a essa prática foram relatados. Uma revisão de 27 estudos sobre o impacto do turismo nas aves relatou em 19 a existência de efeitos negativos (Boyle \& Samson, 1985 apud Sekercioglu, 2002). Como a maioria desses passeios são feitos nos trópicos pouca informação se tem sobre as perturbações porque praticamente nenhuma pesquisa analisando os efeitos do turismo nas aves foi realizada. A maioria das aves são mais sensíveis à perturbação na época da reprodução (Knight \& Cole, 1995 apud Sekercioglu, 2002), o que fica ampliado por muitos praticantes dessa atividade utilizarem cantos gravados de machos para atrair fêmeas, o que pode gerar stress e deserção de ninhos. Aves são sensíveis ao som e às pessoas, portanto é preferível se aproximar delas de carro, devagar, em grupos pequenos e em silêncio para evitar perturbações. 


\subsection{2 - Distúrbio do balanço ecológico}

A perturbação da atividade normal de um animal pode causar a diminuição de sua população fazendo com que a população do seu predador também diminua e aumente a de sua presa. Além disso, o abandono de áreas do seu território devido à alta concentração de turistas expõe seus filhotes a um maior risco de predação. A atividade turística também pode atrair mais predadores para um local por causa do aumento de recurso alimentar nele e, conseqüentemente, aumentar a pressão de predação sobre a população.

Em aves coloniais a deserção dos ninhos com aproximação de grupos turísticos é muito comum, resultando em maior perda de juvenis passeando pelos ninhos, diminuição do cuidado parental e aumento da predação (Burger \& Gochfeld, 1998). Por exemplo, turistas visitando colônias de pingüins na Patagônia aumentaram as taxas de predação de ovos por gaivotas, porque as aves na borda da colônia se afastavam com a aproximação de turistas (Edington \& Edington, 1986 in Roe et al, 1997). Pelicanos marrons tiveram um decréscimo de 52 a 100\% do seu sucesso reprodutivo em áreas de alto fluxo turístico no México (Anderson \& Keith, 1980 in Roe et al, 1997).

A aproximação de turistas também aumentou a taxa de predação de ovos e jovens de jacarés devido à deserção do ninho, fazendo a taxa de predação aumentar de $0 \%$ a 47\% dos ovos para 54\% a 100\% (Edington \& Edington, 1986 in Roe et al, 1997). No entanto leopardos foram muitas vezes auxiliados na caça por veículos turísticos que confundiram a atenção da sua presa (Roe et al, 1997).

Caça esportiva pode ter um impacto de redução da predação sobre as presas potenciais dos animais caçados e um benefício geral para toda a comunidade ecológica. Algumas espécies animais alcançam superpopulações, o que pode causar grandes perdas ao ecossistema local por destruição de vários hábitats e superexploração de recursos. Um 
típico exemplo disso é o caso dos elefantes, que aumentaram grandemente de número após sua proibição de caça para marfim e começaram a danificar a vegetação da savana e das plantações locais. Uma alternativa para isso foi vender a caça de um elefante a praticantes de caça esportiva para regular a população e ainda ganhar lucros (Baskin, 1994; Baker, 1997).

\subsection{3 - Saúde/Doenças}

Problemas de saúde em animais selvagens decorrentes da atividade turística são comuns em grupos de primatas devido à proximidade filogenética ${ }^{4}$. com os humanos. Wallis \& Rick Lee (1999) reuniram uma série de casos de doenças em parques africanos que possivelmente foram causados por turistas (comprovação de causa e efeito na saúde de animais selvagens é muito difícil). Durante um programa de aprovisionamento para habituação de chimpanzés para pesquisa científica no Parque Nacional Gombe na Tanzânia um assistente de campo entregou bananas para uma mãe com dois filhotes e alguns meses depois 11 indivíduos morreram de uma doença respiratória, incluindo os 3 animais. Outras doenças incluem tuberculose, doença viral semelhante à poliomelite, sarna, parasitas, yaws e sarampo em chimpanzés, gorilas, babuínos e guaribas (na Costa Rica) (Wallis \& Rick Lee, 1999). Chimpanzés contaminados com um vírus parecido com o da poliomelite foram alimentados anteriormente com membros paralisados!

Lagartos de parede na Espanha tiveram redução da condição corporal, estado de saúde e aumento da quantidade de parasitas no corpo quando expostos a um alto grau de

\footnotetext{
${ }^{4}$ Dois indivíduos são ditos filogeneticamente próximos quando o ancestral comum destes é recente e, portanto, eles estão se diferenciando evolutivamente há pouco tempo (Futuyma, 1986).
} 
turismo (Amo et al, 2006). Isso se deve ao fato de eles passarem muito tempo fazendo o comportamento de fuga antipredatória em resposta à aproximação de visitantes.

Também pode acontecer a situação inversa: os animais transmitirem doenças para visitantes entrando em suas áreas de vida. Pandey et al (2002) registrou os casos de raiva em turistas e residentes não nativos no Nepal, em que 57\% dos casos de turistas foram por causa de mordida de cachorro e 43\% por arranhão de macacos.

\subsection{4 - Morte de animais individuais}

Com certeza, a morte de alguns animais individualmente é o maior impacto em animais selvagens causado pela caça esportiva. No entanto o efeito drástico causado à sobrevivência de um indivíduo muitas vezes esconde o potencial benéfico que essa atividade pode ter para a comunidade local, tanto humana quanto não humana. Atividade de caça de leões adultos acima de 6 anos de idade, baseado na aparência física, é uma atividade que não causa redução no tamanho populacional (Whitman et al, 2004). No entanto, caça de carneiros no Canadá com grande tamanho de chifres antes de atingir a idade reprodutiva causou uma tendência evolutiva de aumentar na população a freqüência de animais com pequenos chifres e tamanhos corporais (Coltman et al, 2003)

Outros casos de morte envolvem o atropelamento de animais por veículos trafegando dentro de áreas naturais protegidas. Um grupo de sagüis que atravessou uma via dentro do Jardim Botânico de Brasília foi atropelado por um carro em alta velocidade dentro da unidade (observação pessoal). Lebres que se alimentam em gramas próximas a estradas freqüentemente são atropelados por veículos que trafegam a noite no Parque Nacional Kruger na África do Sul (Edington \& Edingto, 1986 in Roe et al, 1997). 
Comedores de carniça costumam se aproveitar dessas mortes acidentais, porém esses detrívoros podem vir a se tornar vítimas potenciais (Roe et al, 1997).

Atropelamentos de pequenos vertebrados, tamanduás, raposas e lobos-guará são comuns no Planalto Central Brasileiro, especialmente nas rodovias próximas às unidades de conservação (parques e reservas). Tal fato ocorre até mesmo em estradas reconhecidas como estradas-parques, a exemplo do asfalto que liga Alto Paraíso de Goiás ao Parque Nacional da Chapada dos Veadeiros, onde a falta de campanhas de conscientização, de equipamentos redutores de velocidade e de travessias tem causado a morte de animais silvestres (Figura 2). A carência de pesquisa científica sistemática tem contribuído para a ignorância e permanência desta situação (Rogério Dias, comunicação pessoal). Várias outras estradas no Brasil também registram um número de atropelamentos de animais provenientes de áreas silvestres (Furtado et al, 2004; De Freitas \& Dias, 2004)

Talvez o caso mais dramático de todos envolvendo mortes foi o dos dingos na ilha Fraser na Austrália. Esse local atrai vários turistas que se dirigem a ele principalmente para observar os dingos e eles são alimentados pelos turistas e até já houve políticas no local para incentivar isso e hoje em dia é legalmente proibido (Burns \& Howard, 2003). Em abril de 2001 dois dingos mataram um garoto de 9 anos de idade e morderam seu irmão de 7 em um feriado. Algumas horas depois as autoridades locais mandaram matar os dois dingos envolvidos no problema. Mais tarde o governo mandou matar mais 29 dingos considerados problema na ilha e que ofereciam riscos aos visitantes (Burns \& Howard, 2003) 


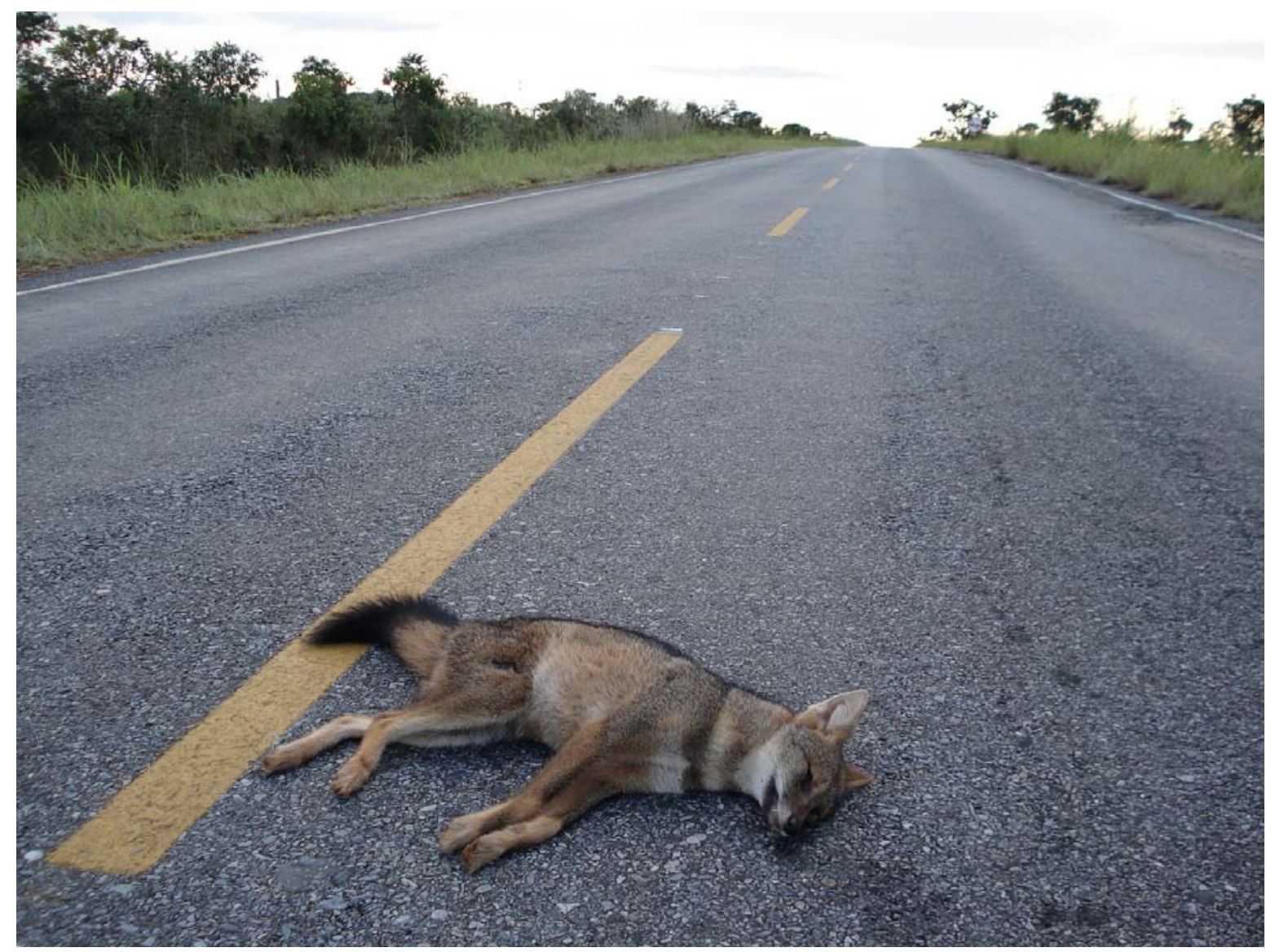

Figura 2. Raposa-do-campo atropelada em estrada no Planalto Central brasileiro. Foto: Rogério Dias.

\section{3 - IMPACTOS INDIRETOS}

A atividade turística traz consigo muitos serviços, construção de infra-estrutura e aumento da energia produzida e do lixo local. São considerados impactos indiretos todos esses efeitos no ambiente que causam alterações no animal, independente do visitante efetivamente entrar em contato visual com o animal.

O maior problema decorrente do desenvolvimento do ecoturismo em uma região é a deposição do lixo, já que comumente a quantidade de lixo produzido antes da implantação da indústria turística no local é mínima. Esse aumento grande de lixo em um local pode 
atrair animais detrítivoros ${ }^{5}$, como urubus e ratos, trazer doenças e tornar a paisagem menos estética. Outras formas de poluição comuns são o aumento do volume de som (afastando muitos animais sensíveis) e poluição da água devido ao esgoto não tratado. De fato, a poluição da água pode afetar significativamente comunidades de recifes de coral aumentando a quantidade de algas e impedindo a penetração de luz (Edington \& Edington, 1986 in Roe et al, 1997). Em outros casos tartarugas em Galápagos engoliram sacos plásticos boiando na água (confundindo com águas vivas) e morreram (Boo, 1990 in Roe et al, 1997).

Também a construção de infra-estrutura turística leva a uma perturbação na vida selvagem, na estética da paisagem local e na dinâmica das populações. Estradas são um grande exemplo de perturbação na dinâmica selvagem fazendo um efeito de barreira e impedindo a travessia de alguns animais para os dois lados da pista e, em alguns casos, favorecendo atropelamentos (Furtado et al, 2004; De Freitas \& Dias, 2004) e a introdução de espécies exóticas, principalmente de plantas como o capim gordura. Trilhas aumentam a compactação do solo, causam erosão e diminuem a densidade da vegetação no local.

A coleta de souvenir natural como pena de uma ave ou uma muda de planta selvagem para um jardim particular também tem grande potencial para causar impactos negativos. Por exemplo, a procura de souvenir das áreas naturais na Bahia estimulam o tráfico ilegal de aves e outros animais silvestres (Leal Filho, 1992 in Roe et al, 1997). Outros impactos são a coleta de madeira para fogueira em acampamentos (eliminando fonte de alimento e abrigo de muitas espécies) e a queima de áreas naturais antes da temporada

\footnotetext{
${ }^{5}$ Detrítivoros são os seres vivos que se alimentam de restos mortais de organismos vivos e facilitam a decomposição da matéria orgânica
} 
turística para atrair animais para o local (Attwell, 1971 in Roe et al, 1997). Um resumo dos impactos é apresentado na tabela 1.

\section{4 - REDUÇÃO DE EFEITOS}

A maioria dos impactos analisados poderia ter sido facilmente evitada se os turistas tentassem não ser notados pelos animais. Essa tentativa de passar despercebido por eles inclui ações como: fazer pouco barulho, ficar em grupos pequenos, se manter a uma distância razoável do grupo animal, não usar e nem carregar objetos ou alimentos muito cheirosos, usar roupas discretas e que se camuflem com a paisagem, evitar a aproximação quando em mau estado de saúde, não alimentar os animais (a menos que incentivado), não sair das trilhas e contratação de um guia responsável (Amodeo, 2004; Burger \& Gochfeld, 1997; Wallis \& Rick Lee, 1999; Orams, 2002). Além disso, As empresas de guias turísticos têm que fornecer educação para seus funcionários para que eles não incentivem os visitantes em ações inconseqüentes (Grossberg et al, 2003)

Alguns instrumentos podem ser muito úteis para minimizar impactos naturais, como é o caso dos binóculos e das máquinas fotográficas com zoom. Esses materiais permitem que as pessoas vejam os animais sem que os animais os vejam e eliminam a necessidade de estar bem próximos a eles para apreciá-los. 
Tabela 1. Lista de fatores envolvidos com impactos turísticos em animais e seus respectivos efeitos ambientais.

\begin{tabular}{|c|c|}
\hline Fator envolvido & Efeitos ambientais \\
\hline Superlotação turística & Stress ambiental, mudanças comportamentais \\
\hline Super desenvolvimento & $\begin{array}{l}\text { Excesso de estruturas feitas pelo homem, ambiente } \\
\text { urbano artificial - poluição visual }\end{array}$ \\
\hline $\begin{array}{l}\text { Atividades recreativas } \\
\text { a) Veículos } \\
\text { b) pesca/caça } \\
\text { c) safáris a pé } \\
\text { d) Esportes de Aventura } \\
\text { (escalada, rappel, } \\
\text { canionning, rafting) }\end{array}$ & $\begin{array}{l}\text { a)distúrbio da vida selvagem, especialmente na } \\
\text { procriação, descanso e forrageamento, poluição sonora } \\
\text { b) Alguns efeitos perturbadores, competição com } \\
\text { predadores naturais } \\
\text { c) distúrbio da vida selvagem, danos na vegetação e } \\
\text { erosão do solo ao redor das trilhas } \\
\text { d) acesso a locais isolados e de difícil acesso causando } \\
\text { abandono de locais de refúgio e reprodução. }\end{array}$ \\
\hline $\begin{array}{l}\text { Poluição } \\
\text { a) barulho } \\
\text { b) lixo } \\
\text { c) depredação }\end{array}$ & $\begin{array}{l}\text { a) Distúrbios de sons naturais, paz selvagem } \\
\text { b) Degradação da cena natural, perigos para a vida } \\
\text { selvagem, ameaças à saúde dos turistas. } \\
\text { c) Mutilação de atrações naturais, roubo de plantas para } \\
\text { jardins particulares }\end{array}$ \\
\hline $\begin{array}{l}\text { Aprovisionamento artificial } \\
\text { a) Alimentação pelos } \\
\text { turistas } \\
\text { b) Buracos de água e de } \\
\text { alimentação }\end{array}$ & $\begin{array}{l}\text { a) mudanças comportamentais, diminuição da } \\
\text { independência, perigo a turistas } \\
\text { b) Concentração incomum da vida selvagem, dano } \\
\text { excessivo na vegetação vizinha }\end{array}$ \\
\hline Veículos & $\begin{array}{l}\text { Mortalidade de animais por atropelamento, danos no } \\
\text { solo e na vegetação, distúrbios na vida selvagem, } \\
\text { poluição do ar e sonora }\end{array}$ \\
\hline $\begin{array}{l}\text { Infra estrutura } \\
\text { a) estradas } \\
\text { b) Cabos de alta tensão } \\
\text { c) Depósitos de lixo } \\
\text { d) Provisões para fogueiras }\end{array}$ & $\begin{array}{l}\text { a) Distúrbios à vida selvagem, atropelamentos, efeito de } \\
\text { barreira, perda de habitat, introdução de espécies } \\
\text { exóticas e efeitos estéticos } \\
\text { b) Perda de vegetação, impactos estéticos } \\
\text { c) Animais problemas, ameaças à saúde, contaminação } \\
\text { da água e do solo, mudança de comportamento de } \\
\text { forrageamento } \\
\text { d) Distúrbios no habitat, pequena mortalidade de } \\
\text { animais, interferência no fluxo de energia do } \\
\text { ecossistema, eliminação de fonte de alimento e local de } \\
\text { abrigo e reprodução. }\end{array}$ \\
\hline $\begin{array}{l}\text { Outros } \\
\text { a) Coleta de souvenir } \\
\text { b) Introdução de plantas e } \\
\text { animais exóticos }\end{array}$ & $\begin{array}{l}\text { a) Remoção de atrações naturais, estimulo ao tráfico de } \\
\text { animais silvestres, quebra de processos naturais. } \\
\text { b) Competição com espécies nativas, alteração da } \\
\text { atmosfera do ambiente natural, confusão pública (?) }\end{array}$ \\
\hline
\end{tabular}

Fonte: adaptado de Thorsell (1984) 
A observação de aves é a maior indústria de turismo de vida selvagem e talvez seja realmente a mais sustentável que existe porque atrai pessoas bem instruídas, incentiva a conservação das aves e traz benefícios econômicos para a comunidade local, geralmente maior do que um passeio de observação tradicional (Sekercioglu, 2002). A caça esportiva, por sua vez, é uma atividade que pode trazer muitos benefícios para a comunidade local, para a conservação da comunidade ecológica e para a unidade gestora da área no que se refere ao aspecto econômico. Para isso acontecer é necessário ter estimativas científicas da população selvagem, cotas compreensivas e aplicadas, gestores honestos e competentes, distribuição dos lucros transparente e justa de modo a favorecer a comunidade local e controle da indústria (Baker, 1997). Ironicamente, um estudo feito analisando a sustentabilidade de quatro tipos de turismo consumidor $^{6}$ e um de não consumidor constatou que o único considerado não sustentável foi o não consumidor (visualização de esquilos) (Prescott-Allen, 1996).

Seguindo essas recomendações simples pode-se realmente alcançar a máxima "tire só fotografias, deixe só pegadas”.

6 Turismo consumidor é aquele que utiliza a vida selvagem diretamente como uma mercadoria (por exemplo, caça esportiva) e o não consumidor apenas o utiliza de forma indireta (como a observação de animais) 


\section{Capítulo 2}

\section{INTERACÕES COM ANIMAIS AQUÁTICOS}

O grupo de animais aquáticos merece um capítulo especial por sua distinção em relação aos terrestres na forma de interação com a população humana, no interesse maior dos turistas, especialmente nos cetáceos ${ }^{7}$, e conseqüentemente dos pesquisadores e na importância econômica e crescimento dessa indústria. Os animais aquáticos considerados aqui correspondem aos cetáceos, peixes, corais e alguns répteis.

De forma geral a maioria desses animais realiza interações não só com o homem em si, mas com embarcações utilizadas pelos humanos para se aproximarem deles. Outra forma de interação possível é a realização de mergulhos com o auxílio de um cilindro ou um snorkel.

\subsection{EMBARCAÇÕES}

O uso de embarcações para se aproximar de animais dentro d'água é uma atividade que possui um potencial impacto alto na vida selvagem pela possibilidade de distúrbios sonoros e ferimentos físicos que interfiram no comportamento normal do animal. O turismo de observação de baleias ${ }^{8}$. é o principal causador de impactos na vida selvagem por causa de sua rápida expansão pelo mundo inteiro e grande importância econômica dessa indústria.

\footnotetext{
${ }^{7}$ Cetáceos é uma ordem taxonômica de mamíferos aquáticos (baleias, golfinhos e botos)

8 Turismo de observação de baleias ou "Whale watching" é definido como turismo por barco, ar ou terra, formal ou informal, com pelo menos algum aspecto comercial, para ver, nadar com e/ou ouvir a qualquer uma das 83 espécies de cetáceos (Hoyt, 2001).
} 
Em 1991, quatro milhões de pessoas observaram baleias, em 1994, foram 5,4 milhões de pessoas e em 1998, mais de 9 milhões participaram dessa atividade turística, o que corresponde a um crescimento médio de 12,1\% ao ano. Em termos econômicos, o total que turistas gastaram diretamente nessa indústria passou de 77 milhões de dólares em 1991 para 299,5 milhões em 1998, o que corresponde a uma média de crescimento anual de 21,4\% (Hoyt, 2001).

Essa indústria expandiu para 87 locais no mundo e para todos os continentes do planeta, incluindo a Antártica (Hoyt, 2001). Devido ao fato de muitos desses animais realizarem migrações anuais para se reproduzir e depois retornarem em busca de fontes alimentares abundantes em águas frias, desenvolveu-se estruturas de observação em vários pontos do trajeto de um mesmo grupo. Esse acúmulo de interação em diferentes locais pode resultar em acúmulo de stress e afetar a sobrevivência e reprodução de animais ameaçados de extinção.

A maior parte da observação de baleias, 72\%, ocorre dentro de embarcações, como barco, navio, bote, lancha e caiaques, e apenas 28\% ocorrem em terra firme (Hoyt, 2001). Essa tendência na forma de observar em embarcações se deve, em grande parte, ao fato das operadoras de turismo e grande parte do trade turístico acreditar na premissa que os turistas são motivados a procurar essa atividade para chegar bem próximo dos animais (figura 3). No entanto, Orams (2000) aplicou 704 questionários em 12 expedições turísticas embarcadas na Austrália e percebeu que a proximidade espacial dos turistas em relação às baleias não é um fator determinante na satisfação. Muitos turistas retornam satisfeitos sem nem mesmo avistar baleias no passeio. Portanto, o turismo de observação de baleias não é somente chegar próximo das baleias, muitas outras variáveis estão envolvidas como: o 
número de pessoas a bordo, comentários durante a viagem, o serviço proporcionado pela tripulação, a duração do passeio, a posição do barco, o modelo do barco e outras atrações.

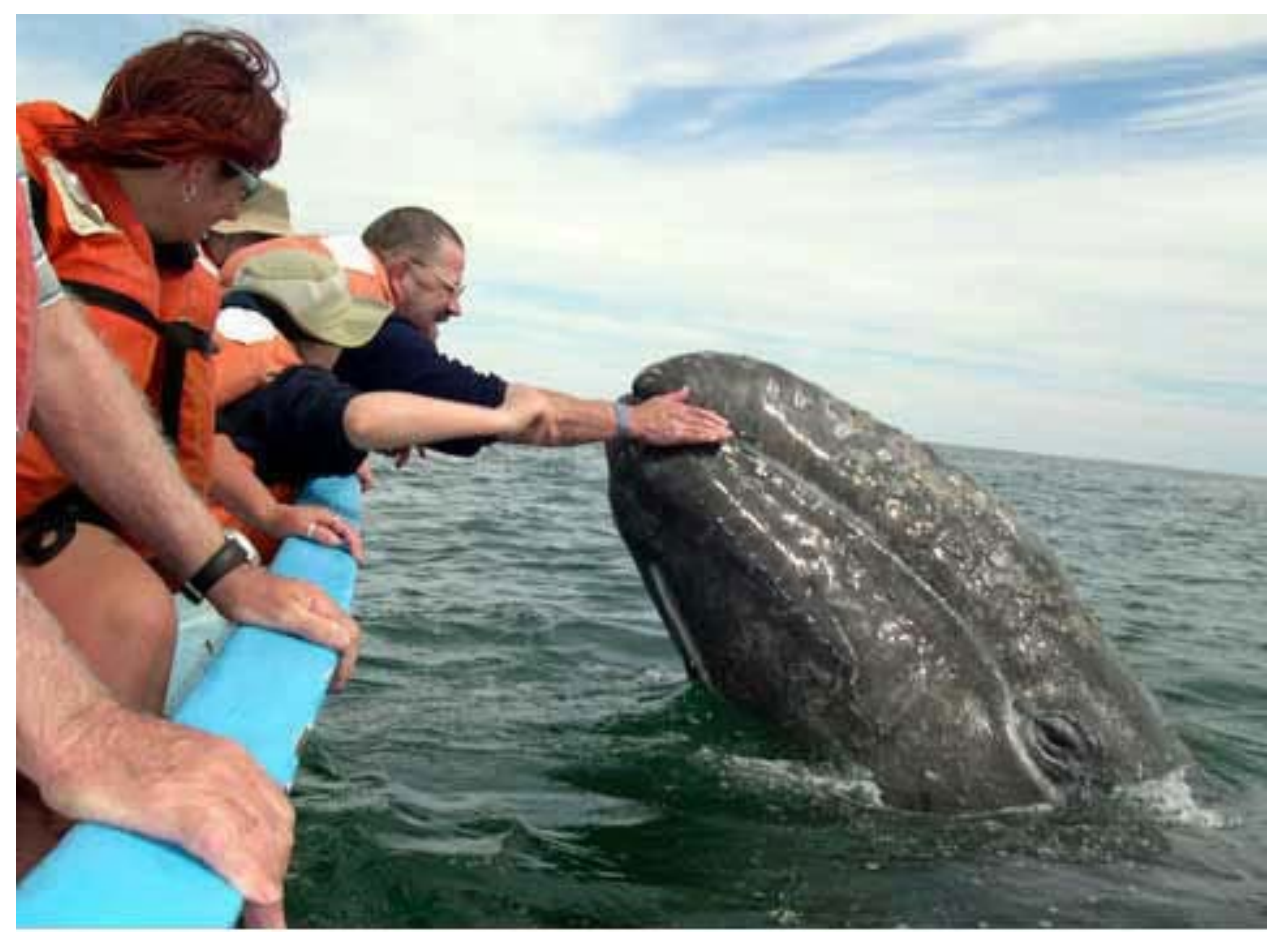

Figura 3. Exemplo extremo de proximidade espacial de embarcações turísticas a baleias selvagens. Extraído de http://www.calnaturalist.com/whale.html.

O fato é que, em certos locais o número muito grande de barcos em determinadas épocas do ano causa mudanças no comportamento dos animais, que podem ser de curto ou longo prazo. Respostas de curto prazo rapidamente desaparecem assim que o estímulo é retirado e as de longo prazo podem permanecer por muito tempo prejudicando a sobrevivência e a reprodução dos indivíduos do grupo.

Esse problema se torna ainda maior quando a população de cetáceos é residente em um local fechado e pequeno, como nos fiordes da Noruega. A resposta comportamental de curto prazo de golfinhos nariz de garrafa (Tursiops ssp.) foi analisada com e sem interação com barcos de turismo por Lusseau (2003) nesses fiordes.Os comportamentos de 
socialização e descanso foram reduzidos significativamente e houve um aumento de mergulho e viajando, indo todo o grupo para uma direção determinada com velocidade maior que a do barco, quando na presença de embarcações turísticas. Os grupos só passavam 9\% do tempo em contato com embarcações e, portanto, o impacto destas não chegou a mudar o padrão comportamental por causa de sua baixa intensidade.

Em outros estudos Lusseau (2004) esses mesmos golfinhos foram estudados em dois fjiords na Noruega com diferentes intensidades de turismo. Os golfinhos na área mais impactada saíram do fjiord em momentos de alta movimentação de barcos e na outra área a resposta foi apenas de curto prazo. A população de Milford Sound está sendo muito impactada pelo turismo ao contrário da de Doubtful Sound estudada no artigo anterior. Pode-se observar com estes estudos que o turismo pode sim causar um impacto de longo prazo em populações selvagens de cetáceos, entretanto com uma boa gestão da atividade turística esses impactos podem ser minimizados a um ponto responsável.

Richter et al (2006) estudou os impactos de barcos e aviões em cachalotes na Nova Zelândia e descobriu que intervalos respiratórios, tempo na superfície e tempo para o primeiro clique variaram na presença de barcos e aviões. No entanto, a resposta em animais residentes no local foi menor que em animais de passagem, o que pode indicar que as cachalotes residentes se adaptaram ao tráfego de barcos e aviões e reconhecem como inofensivos. A mudança nos comportamentos da baleia pode causar diminuição na taxa de alimentação, na taxa de respiração e pode indicar redução da eficiência da ecolocalização ${ }^{9}$.

9 Ecolocalização é a forma de se localizar no ambiente através da emissão e recepção de pulsos sonoros de alta freqüência, de forma semelhante a um sonar. Presente principalmente em morcegos e golfinhos. 
As respostas de curto prazo podem ser divididas em seis categorias de mudanças comportamentais: i) padrão de mergulhos e superfície, ii) velocidade de natação, curso e orientação, iii) dispersão do grupo, iv) orçamento de atividades, v) eventos comportamentais e vi) padrão de distribuição e uso do habitat (revisão em Bejder e Samuels, 2002). Na categoria “i” a resposta usualmente é aumentar o intervalo entre as respirações (principalmente em fêmeas com filhotes), diminuição do tempo na superfície e do número de respirações. Para a categoria "ii” o efeito pode se dar atraindo e depois repelindo golfinhos ou fazendo-os nadar mais rápido para fugir do barco, enquanto na categoria “iii” o normal é o grupo permanecer bastante coeso para se proteger do contato com embarcações. Para “iv” mudanças do tipo diminuição do cuidado maternal com os filhotes em áreas de alimentação de animais selvagens, indivíduos interagindo com humanos por $75 \%$ do seu tempo diário e diminuição significativa do tempo socializando são comuns. As respostas do tipo “v” são analisadas quando se tem um conhecimento maior da espécie e que permite dizer qual comportamento simboliza estresse ou habituação a humanos quando está presente ou ausente, por exemplo, agitação de golfinhos no período normal de descanso quando em contato com barcos. Quanto à categoria “vi” os animais geralmente forrageiam em locais que não correspondem aos de maior abundância de alimentos na presença de embarcações ou diminuem seu habitat para aqueles locais onde ocorre alimentação e se tornam mais agrupados.

Já respostas de longo prazo são raras na literatura, pois estudos de longos anos acompanhando mudanças comportamentais de cetáceos em relação ao turismo demoram, são caras e necessitam muita persistência. No entanto, são conhecidos alguns casos em que os animais se tornaram habituados à presença do homem (ver golfinhos solitários sociáveis à frente; WDCS, 2005), mudaram sua área de alimentação ou de vida em períodos de alta 
atividade turística (Lusseau, 2004), diminuíram sua área de vida em decorrência de alimentação por turistas e, devido a esses fatores, tiveram uma diminuição de seu sucesso reprodutivo ${ }^{10}$.

Outra atividade turística com animais marinhos bastante difundida por todo o globo é a prática da pesca esportiva. É questionável a atitude ética dessas atividades e a sua interferência para o bem-estar dos animais procurados. Apesar de muitos praticantes da pesca esportiva argumentarem que a prática não prejudica os animais porque eles não sentem dor na região afetada, Balon (2000) argumenta que a questão não é centrada na dor, e sim no prejuízo individual e para o grupo que essa atividade proporciona. Ela cita que o estresse causado por uma luta prolongada de um peixe contra um pescador pode causar stress em níveis tão altos que é capaz de causar uma falha em todo o sistema fisiológico do animal e levá-lo à morte. Outro problema também ocorre no caso da modificação de ambientes aquáticos naturais com a introdução de espécies exóticas para melhorar a eficiência de captura do hobby, como foi o caso da introdução do salmão do pacífico nos Grandes Lagos do Canadá e do tucunaré no Brasil (Balon, 2000; Cota et al, 2002).

\subsection{1 - Interações sonoras}

Cetáceos odontocetes (golfinhos e botos) utilizam sinais sonoros de alta freqüência para se localizar no ambiente ou para caçar em águas não próprias para a visão (Pough et al, 1999). Outros cetáceos, como a baleia azul, utilizam sinais sonoros para comunicação a

\footnotetext{
10. Sucesso reprodutivo é uma medida do número de descendentes férteis que um indivíduo consegue produzir durante toda a sua vida. Um indivíduo de alto sucesso reprodutivo consegue espalhar seus genes na população mais rapidamente e assim é favorecido por seleção natural.
} 
grandes distâncias entre os indivíduos da mesma população. Barulhos produzidos pelos barcos e aviões podem afetar a comunicação social e a ecolocalização nos cetáceos?

Green \& Au (2000) estudaram o efeito de cinco embarcações diferentes sobre o comportamento da baleia jubarte (Megaptera novaeangliae) em duas estações do ano com níveis diferentes de turistas. De acordo com esse estudo o barulho produzido pelas embarcações não danifica o sistema auditivo das baleias, já que está abaixo do barulho máximo produzido por elas e presente no ambiente marinho. No entanto, ficou claro que os sons são audíveis pelos animais analisados e que aqueles ruídos que causam maior perturbação são os mais altos e os mais complexos (mais bandas).

Constantine (1999) revisou as pesquisas feitas na Nova Zelândia com o barulho das embarcações e descobriu, entre outras coisas, que os animais conseguiam reconhecer as embarcações pelo som que produziam e podiam evitar as indesejadas. Em momentos como a ignição de um barco e quando os turistas entraram na água golfinhos nariz de garrafa emitiram um som conhecido com "ratchet" produzido em períodos de raiva ou alarme (Helweg 1995, in Constantine 1999). Em dois momentos em que os turistas entraram na água os golfinhos ficaram em silêncio, porém não se sabe se esse silêncio é uma reação para a proteção ou para acessar o comportamento dos turistas.

Outros estudos em outras partes do mundo demonstraram respostas variadas às interações sonoras. Lesage et al (1999, in Samuels \& Bejder 2002) mostrou que aproximações experimentais de barcos induziram em baleias belugas durações de canto mais longas, mudanças na taxa de vocalização, aumento na freqüência dos sons e uma tendência para emitir cantos repetitivamente e maior resposta ao menor e ao maior barco. Essa resposta parece ser para compensar o barulho e aumentar a detecção do sinal por parte 
dos seus conspecíficos ${ }^{11}$. Richter et al (2006) mostrou que cachalotes residentes começam a vocalizar mais cedo na presença de embarcações e as passageiras vocalizam mais cedo na presença de aviões. Esse resultado sugere que os animais começam a vocalizar mais cedo para compensar o aumento no barulho e, portanto, sua ecolocalização fica prejudicada.

No entanto, cetáceos são animais sociais e muito inteligentes de forma que cada indivíduo possui uma personalidade própria e características únicas. Desse modo não se deve generalizar os impactos sonoros em alguns cetáceos para todo o grupo. Com baleias jubarte (Megaptera novaengliae) foi tocado um som “playback” e resultou em diversas respostas individuais: algumas baleias pararam de cantar, outras aumentaram a duração dos seus cantos e outras não mudaram seu comportamento normal (Miller et al 2000, in Samuels \& Bejder 2002). O impacto dessas interações naqueles indivíduos que param de vocalizar ou que vocalizam mais pode afetar o sucesso reprodutivo já que o canto é entendido como caractere de seleção sexual.

\subsection{2 - Encontros na água}

A procura por contato com animais selvagens em ambiente natural inclui uma gama muito maior de possibilidades, deixando de se restringir principalmente à observação de mamíferos marinhos para englobar toda a prática de mergulho, com snorkel ou cilindro, em ambiente com rica vida selvagem. Essa categoria de interação será classificada dentro de interações com embarcações porque a grande maioria dos mergulhos em um ambiente de vida selvagem se dá a partir de barcos, ao ponto de, em alguns casos, não se conseguir

${ }^{11}$ Conspecíficos são animais pertencentes à mesma espécie. 
separar com clareza os impactos advindos do mergulho ou do barco (Constantine, 1999; Tratalos \& Austin, 2001)

Para a observação de baleias não há consenso entre as legislações dos países sobre se esta atividade deve ser permitida ou não. Em países como Austrália e Nova Zelândia existem legislações específicas para regular e gerir a execução desses passeios enquanto países como Japão não possuem legislação tratando do assunto e outros como Estados Unidos e Brasil proíbem em legislação tal atividade por considerar danosa aos animais (porém nos dois países ocorrem passeios ilegalmente) (Constantine, 1999; Frohoff \& Packard, 1995, Santos, 1997 in Constantine, 1999; IBAMA, 1996). Essa discussão sobre a possibilidade de legalização da atividade em cada país já proporciona uma idéia de que esta atividade é potencialmente mais impactante para os animais e também pode ser ainda mais para os turistas envolvidos no contato.

Apesar disso, essa indústria cresce rapidamente em grande parte do mundo e em poucos locais a regulação é controlada por um rigoroso processo de gestão, como é conhecida a prática na Nova Zelândia. Uma revisão por Samuels et al (2003) de mergulhos com cetáceos selvagens com enfoque no hemisfério sul levantou 30 locais em que esta atividade ocorre e seus possíveis impactos a partir de dados de literatura e de comunicação com envolvidos no processo, quando dados eram escassos. Quatro categorias de mergulho com golfinhos foram delimitadas pelo uso habitual de tais práticas: mergulho com golfinhos solitários sociáveis (ver abaixo), aprovisionados com comida humana, habituados e não habituados. Apesar dos impactos dessa atividade serem potencialmente maiores que a aproximação com barco é difícil de distinguir se o efeito se dá devido ao barco ou aos turistas na água, portanto os impactos são similares nos dois casos. No entanto, os barcos em passeios com mergulhos com cetáceos geralmente precisam dispor de estratégias para 
parar os golfinhos de modo a facilitar o mergulho. Isso pode se dar de três formas: posicionando-se à frente e ao lado do curso dos golfinhos, no curso dos golfinhos (de forma que os golfinhos são obrigados a parar ou desviar do barco!) e em volta do barco quando os golfinhos o estão rodeando. Quando os banhistas entram na água no curso dos golfinhos o impacto é muito significativo e os golfinhos progressivamente evitam as pessoas nesta situação ao contrário das outras estratégias (Constantine, 2001 in Samuels et al 2003).

Os mergulhos para encontro de animais selvagens em ambiente natural também têm gerado impactos em várias comunidades de recifes de coral. Apesar desse ecossistema marinho ser mais resistente, devido à sua comum estrutura de calcário rígido, o constante pisoteio por grupos de turistas e depredação mecânica para enfeitar aquários ou para servir como souvenir está causando sérias modificações na estrutura da comunidade local.

Tratalos \& Austin (2001) compararam áreas de recifes no Caribe expostas a altas e baixas intensidades de turismo e não expostas à mergulhadores. Eles observaram que houve uma redução significativa na cobertura de corais rígidos nas áreas de alto número de mergulhos e um aumento conforme se distanciava dessas áreas, assim como um maior número de fragmentos de corais mortos nesses locais. Apesar do relevante impacto biológico nessa comunidade o principal efeito talvez seja a diminuição da beleza do local, o principal fator motivador da procura por corais. Uma grande redução da estética no local pode fazer com que o fluxo de turistas mude para outro local mais bonito, tornando a atividade turística não sustentável.

Já Hawkins \& Roberts (1993) investigaram o efeito do pisoteio em áreas de coral no mar vermelho egípcio comparando trilhas nos recifes que servem de ligação da praia até o limite dos recifes. As comunidades biológicas não mudaram drasticamente, mas a estrutura foi significativamente alterada de modo que nas trilhas os corais eram menores e possuem 
menos ramificações, a cobertura de corais era menor e havia menos colônias de corais. De forma geral essas modificações na estrutura também contribuíram para diminuir a beleza do local.

Mas com uma constante proliferação no mundo de áreas de proteção marinha a conservação dessas comunidades parece não ter aumentado (McClanahan, 1999). O problema parece vir do conflito surgido entre os gestores do parque e os mergulhadores que o utilizam de forma recreativa e, muitas vezes, irresponsável. Uma variável que falta para muitos parques e que pode ajudar a minimizar os impactos do mergulho é o cálculo da capacidade de carga do local para manter os movimentos a um ponto sustentável ecologicamente (Davis \& Tisdel, 1995)

Uma proposta ousada para diminuir os impactos sobre os recifes de coral naturais foi sugerida por Treeck e Schuhmacher (1998) e consiste na construção de recifes de corais semi-artificiais através do uso de um equipamento que quebra eletricamente compostos abundantes no mar e os transforma em carbonato de cálcio. Esse equipamento pode fornecer substratos ideais para a fixação de corais (assim como ocorre com embarcações afundadas) e aliviar a pressão sobre áreas naturais em unidades de conservação.

\section{2 - INTERAÇÕES EM TERRA}

Outros animais marinhos sofrem fortemente com os impactos advindos de interação em terra firme, principalmente os pinipedes ${ }^{12}$. Os efeitos desse contato em espécies de focas causaram modificações desastrosas no comportamento e sobrevivência de algumas

\footnotetext{
12. Pinipedes é uma ordem de mamíferos que, junto com cetáceos, sirenia e alguns carnívoros, constituem os mamíferos aquáticos. Representantes dessa ordem incluem focas, leões marinhos e elefantes marinhos.
} 
populações levando certas espécies a extinções locais e, possivelmente, à extinção completa (Johnson \& Lavigne, 1999).

O esforço de pesquisa sobre efeitos do turismo em populações de pinipedes é muito pequeno no mundo inteiro, de forma que não se tem muito conhecimento científico sobre o contato humano com esses animais. Constantine (1999) levantou os trabalhos realizados com focas e leões marinhos na Nova Zelândia e no mundo. Um estudo indicou que a presença de turistas a menos de 10 metros de leões marinhos não era tolerada pelos animais. Outro indicou o contrário com a mesma população alguns anos depois, o que pode significar habituação ao contato com pessoas nessa população (Beentjes 1989, Wright 1998 in Constantine 1999). Alguns relatos existem de turistas jogando pedras nos grupos de leões marinhos, excitando ou se aproximando deles para conseguir fotografias melhores, em que os animais responderam atacando os visitantes ou fugindo do local (Heinrich, 1996 in Constantine 1999). Aumento da agressão foi anotada em grupos em Galápagos e na Califórnia, devido ao grande fluxo de turistas e ao aprovisionamento de comida das pessoas para os animais (os animais agora perseguem e atacam pessoas para conseguir comida). Outros efeitos foram a redução do cuidado mãe e filhote e o assassinato de alguns filhotes na Austrália.

Focas também respondem ao aumento da atividade turística se afastando ou aumentando o tempo vigiando contra predadores, ou em alguns casos elas se habituam e param de responder aos estímulos, menos nos períodos de reprodução. Aliás, a época da reprodução coincide na Nova Zelândia com o pico de maior fluxo de turistas e o impacto sobre as fêmeas com filhotes ou grávidas é muito provável. Na Inglaterra, fêmeas com filhotes aumentaram a agressividade e a vigilância contra os turistas, o que resultou em menos tempo de lactação e maior mortalidade dos jovens (Lidgard, 1996 in Constantine, 
1999). Algumas focas foram cercadas por turistas por terra e mar o que fez com que, no momento que algumas focas caíram na água para fugir da aproximação de visitantes a pé, encontraram grupos de turistas querendo nadar com focas. Isso pode provocar aumento na atividade agressiva do animal com um maior número de ataques e mordidas (Constantine, 1999).

Talvez o caso mais problemático de impacto do turismo sobre animais aquáticos seja o da foca monge que vivia ao longo da costa do Mediterrâneo (Johnson \& Lavigne, 1999). A foca monge foi submetida à intensa pressão de perda de habitat para construções (principalmente de hotéis e infra-estrutura turística) caça e pesca e perturbação por turistas (Figura 4 a) em uma área que recebia em 1980 um terço de todo o fluxo turístico global. Isso resultou em sua extinção de áreas em que ocorria originalmente como: Itália, Croácia, França, Espanha e Tunísia e o seu confinamento em duas regiões pequenas. A espécie está entre as doze espécies de animais com o maior risco de extinção no mundo e pode vir a se extinguir muito em breve.

Uma alternativa viável, barata e eficiente para a gestão dos impactos dos visitantes sobre focas e leões marinhos é a construção de cercas que separem as áreas de reprodução e descanso da entrada de turistas. Cassini et al (2004) relatou que a construção de uma cerca em Cabo Polônio, no Uruguai, diminuiu as respostas à aproximação de turistas, ao comportamento intrusivos destes, à grupos grandes de visitantes, diminuiu as respostas de agressão às pessoas e aumentou o número da população no local. Esse resultado mostra que a instalação de cercas pode minimizar as respostas mais agressivas e estressantes nos animais.

Tartarugas marinhas também servem de atração turística em vários locais do mundo. No Parque de Conservação Mon Repos na Austrália, o fluxo de turistas na região tem 
crescido em busca de contato com esses animais marinhos e isso pode ajudar a conservação da espécie reduzindo a pressão de caça sobre ela (Wilson \& Tisdell, 1999). No entanto, esse auxílio na conservação não será significativo se não for uma iniciativa global, já que esses animais fazem rotas migratórias extensas (Wilson \& Tisdell, 1999; Tisdell \& Wilson, 2002). No Brasil, as atividades de pesquisa e conservação do projeto Tamar têm auxiliado na conscientização da população e na conservação dos animais ao longo da costa (observação pessoal)

\section{3 - GOLFINHOS SOLITÁRIOS SOCIÁVEIS}

Existem diversos casos no mundo de golfinhos que adquiriram um nível de habituação e de interação com os humanos tão forte que se separam do grupo para permanecer em contato com a população humana por mais tempo (revisão em WDCS, 2005). Esses golfinhos procuram ativamente o contato com os turistas ao invés de seu grupo familiar e isto acaba atraindo mais turistas ao local pela facilidade de se relacionar com um animal selvagem em ambiente natural sem muito esforço. Esses casos geralmente ocorrem em animais que são alimentados regularmente por turistas e pela população residente, em áreas de natação com golfinhos e é mais observado em juvenis do que em adultos.

Em um relatório publicado pela WDCS (Whale and Dolphin Conservation Society) foram enumerados 56 casos de golfinhos que se tornaram solitários e sociáveis em vários locais do mundo, muitos deles famosos por sua importância econômica para a indústria turística local. Esses animais se tornam de certa forma amigos dos visitantes e da população local a ponto de receberem apelidos como Maui, Georges e Tião. Esse tipo de comportamento é mais comum de ocorrer em golfinhos nariz de garrafa, mas também pode 
ocorrer em belugas (Delphinapterus leucas), orcas (Orcinus orca), golfinho comum (Delphinus delphis), tucuxi (Sotalia fluviatilis) e outras espécies.

O aumento da interação homem e animal frequentemente expõe os dois lados a um nível maior de perigo e injúrias provenientes desse relacionamento (Fig. 4 b e c). Samuels et al (2002) relataram em um levantamento desses casos que é freqüente os golfinhos morrerem (10 de 28 casos), sofrerem com poluição (3), colidirem com barcos (8), ficarem doentes (7) ou se ferirem (4) durante essas interações. É importante ressaltar que devido à falta de pesquisa e de anotações sistemáticas sobre impactos no comportamento, muitos animais não tiveram informações suficientes disponíveis e isto pode subestimar o risco de injúrias nos animais.

O impacto previsto sobre esses animais é maior do que em outros. Como em geral isso se desenvolve enquanto o indivíduo é jovem, por causa de uma maior predisposição de órfãos e jovens desmamados a procurar interações, comportamentos essenciais para a sobrevivência do indivíduo podem não se desenvolver de forma correta e comprometer o sucesso reprodutivo individual. Devido a uma maior exposição a situações possivelmente estressantes o número de agressões geralmente aumenta (tanto para turistas quanto para golfinhos) e ocorre comportamento sexual de golfinhos dirigido a humanos, talvez devido a um erro de aprendizado no desenvolvimento. O caso mais extremo relatado ocorreu com “Tião”, um golfinho nariz de garrafa em São Vicente - SP, em que um grande número de maus tratos dirigido a este animal, como colocar cones de sorvete no opérculo respiratório, resultou em um aumento de agressividade e 29 pessoas feridas e 1 morta. Ele foi provavelmente morto em retaliação à morte de uma criança (Santos, 1997 in Constantine, 1999; WDCS, 2005). 




Figura 4. Fotos de interações com muito perigo para o animal. (a) turistas se agregam muito próximos a uma foca monge, gerando uma situação de grande estresse para o animal. (b) e (c) golfinhos interagem com turistas em embarcações, correndo risco de se machucar com a hélice do barco ou contrair uma doença. Fonte: Johnson \& Lavigne, 1999; WDCS, 2005. 


\section{Capítulo 3}

\section{SITUACÕES E PERSPECTIVAS BRASILEIRAS}

A indústria do turismo de natureza no Brasil merece atenção especial, já que até hoje pouca atenção foi fornecida aos impactos dessa atividade no meio ambiente natural e na vida selvagem. A quantidade de estudos científicos examinando os impactos do turismo na vida selvagem é pequeno e, portanto, grande parte das informações apresentadas aqui são de origem pessoal ou de comunicação com pessoas envolvidas na atividade.

O Brasil é o país da megabiodiversidade porque dentre todos os países é o que possui a maior biodiversidade. Isso se deve a grande quantidade de espécies em todas as classes animais, a ampla variedade de ecossistemas e formas de vida diversas sustentando paisagens e vida selvagem de grande valor turístico. De cada cinco espécies conhecidas uma se encontra no Brasil, sendo que é o primeiro lugar em biodiversidade de plantas e de mamíferos.

A falta de planejamento, pesquisa e fiscalização das normas ambientais presentes no país provoca graves danos ambientais por parte de atividades turísticas. Em especial, a vocação para o turismo de mar e sol tem causado grandes aglomerações imobiliárias no litoral e acabando com áreas de mangue e de restinga importantes para a manutenção das comunidades vegetais e animais.

Visto isso, esse capítulo tratará dos tipos de turismo de vida selvagem praticado no Brasil e sugestões para a melhoria dos já implementados e possibilidades de implementações de forma sustentável em alguns locais. 


\section{1 - SAFÁRI}

O termo safári tipicamente é associado à África e à observação ou caça de grandes mamíferos da savana africana. No entanto, vamos considerar como safári toda a atividade de observação de mamíferos terrestres em ambiente naturais.

A atividade de safári atrai turistas do mundo inteiro para observar grandes mamíferos da savana africana e tem a preferência por animais maiores. Os cinco principais animais que movimentam essa indústria no continente africano são elefante, leão, leopardo, rinoceronte e búfalo (Chacra, 2005) e são conhecidos como "grande cinco". Pelo fato de o Brasil não possuir esses animais em meio natural ele perde em competitividade nesse setor e acaba descaracterizando-o, pois esses animais estão no imaginário do público quando imaginam um safári. Talvez isso explique porque esse termo não é geralmente usado no turismo brasileiro.

De acordo com Newlands (1997) depois de animais grandes outros aspectos essenciais no turismo de vida selvagem são animais ameaçadores, em grandes números e bem próximos dos turistas. Com essas características existem poucos animais brasileiros e, geralmente, um animal assustador, como a onça-pintada, está em extinção e não existe em grandes números e nem se pode chegar próximo. Devido às peculiaridades desse setor, os safáris no Brasil ocorrem com a população local (muitas vezes acidentalmente dentro de um outro passeio) e para turistas internacionais especializados, ou seja, que colecionam observações de todos os animais dentro de um grupo específico.

Para esse público o principal grupo de mamíferos que o Brasil apresenta para observação são os primatas, entre eles animais bastante comuns como sagüis (Callithrix spp.), macacos-prego (Cebus spp.) e micos de cheiro (Saimiri spp.) e animais mais raros como bugio (Alouatta spp.), mico-leão-dourado (Leontopithecus rosalia), uacari (Cacajau 
calvus) e macaco da noite (Aotus spp.). Existem outros mamíferos que servem de atração para visitantes que se deparam com eles, muitas vezes por acidente, como os quatis (Nasua nasua), cervos, tamanduás, lobinhos, raposas e tatus.

\subsection{1 - Observação de primatas}

O Brasil possui a maior diversidade de primatas (103 (IBAMA, 2007)) com o dobro de espécies da República Democrática do Congo, o país com a segunda maior riqueza de primatas. Apesar de não possuir animais famosos como orangutangos, gorilas e chimpanzés a diversidade existente guarda um grande número de animais bonitos, espertos e carismáticos. A exemplo disso existe o mico-leão-dourado que atraiu com seu carisma a atenção de diversas pessoas no mundo para a sua conservação, o que ajudou a restabelecer áreas naturais grandes (ver www.micoleao.org.br.).

Em geral, a observação de primatas em áreas naturais brasileiras ocorre de forma acidental no meio de outras atividades que os visitantes possam estar praticando. Sabbatini et al (2006) relata que apenas $10 \%$ dos visitantes de fim de semana do Parque Nacional de Brasília e 3\% dos visitantes de dia de semana vão ao parque para ver os macacos-prego (Cebus apela libidinosus). A maioria dos visitantes do parque percebem a unidade como uma área de lazer e esporte e não como área natural protegida por lei, o que resultou no apelido “água mineral”, devido às piscinas de água natural potável.

Um fator muito comum na interação entre humanos e primatas selvagens é o fornecimento de alimento artificial para os macacos (Figura 5). No caso de primatas, muitas vezes o aprovisionamento ocorre sem a intenção das pessoas em alimentar os animais, porque os macacos podem iniciar a utilização desse recurso alimentar explorando lixeiras e 
depois quando já estão habituados, roubam o alimento dos visitantes de forma mais agressiva (Martins, 2005; Sabbatini et al, 2006).

No Parque da Criança em Anápolis-GO, Martins (2005) analisou a interação dos visitantes do parque com os macacos-prego locais e constatou que o transporte de alimentos é um fator importante para a ocorrência de interações conflituosas. Os tipos de alimentos fornecidos para os animais incluem tanto alimentos naturais como bananas e outras frutas quanto alimentos artificiais como coca-cola, cerveja e pipoca. Essa habituação ao aprovisionamento de visitantes por parte dos animais resultou em um aumento da atividade agressiva, registrando oito casos de mordidas em dois meses de estudo. A ação de oferecer e retirar o alimento, de interromper momentos de brincadeira entre os infantis e perturbação do grupo quando na proximidade de filhotes recém nascidos, aumentou a agressividade dos animais (Martins, 2005).

Rocha (2003) estudou uma população de macacos-prego no Bosque Bougainville em Goiânia-GO que era constantemente alimentada pela população local do bairro. Grande parte dos alimentos vinha de uma moradora que todo o dia antes das 9 e depois das 16 horas fornecia comida aos macacos. Os itens alimentares fornecidos incluíram principalmente frutas como banana, manga e melancia e também outros alimentos como cenoura, pão, doces, bolachas, pão de queijo e água. Os animais se encontraram habituados ao fornecimento de alimentos pelos moradores locais, principalmente em relação ao item água que foi $98 \%$ fornecido artificialmente por pessoas e os macacos ingeriram muito mais frutas do que o normal para a espécie. Outra população de macaco-prego em Goiânia bastante habituada a alimentação humana existe no Campus da Universidade Federal de Goiás, onde os animais constantemente pegam comida da lixeira perto da lanchonete e já 
foram observados chupando drops de menta, comendo pipoca, pão e doces e bebendo refrigerantes na lata (Mendes, 2006; Mendes et al, 2005).

No Parque Nacional de Brasília também existe uma população de macacos prego com uma forte interação com os visitantes em busca de comida. Nesse local 53,2\% da comida fornecida foram frutas, 16,3\% alimentos cozidos e molhos (catchup e maionese), 10,3\% estão dentro de sacos plásticos (salgadinhos), 9,3\% doces, 5,3\% misturas, 5\% bebidas e $0,7 \%$ leite ou derivados (Sabbatini et al, 2005). Outra pesquisa mostrou que 63,2\% dos alimentos consumidos por essa população são fornecidos e destes $57,3 \%$ são alimentos artificiais (Pinha et al, 2004). O Parque Nacional de Brasília já teve um caso de doença transmitida dos macacos para um senhor de idade que os alimentava com freqüência (L. Pangela, comunicação pessoal).

Já no Parque Estadual Rio Doce em Minas Gerais uma população de macaco-prego (Cebus nigritus) varia sua dieta conforme a sazonalidade do fluxo turístico, ingerindo mais itens artificiais e explorando mais as lixeiras do parque na época de maior visitação (Ferreira, 2005). Porém, essa população não se apresentou habituada ao fornecimento de alimento pelos visitantes, já que em todos os períodos os itens naturais na dieta se apresentaram em maior proporção do que os fornecidos (Collombini et al, 2004).

Cebus nigritus (espécie de macaco-prego) aprovisionados experimentalmente no Parque Nacional Foz do Iguaçu tiveram uma diminuição da mortalidade infantil (Ferreira, 2005), mostrando que essa prática pode ajudar a conservar essa espécie se bem administrada.

Os macacos-prego são geralmente mais propensos a ter interações com humanos por sua grande curiosidade e inteligência, o que os possibilita a, por exemplo, abrir as lixeiras para pegar alimentos. No entanto, outros primatas também exibem habituação a 
alimentos fornecidos por pessoas dentro de unidades de conservação ou dentro da casa da pessoa que os alimenta. Um bom exemplo é o sagüi que é praticamente domesticado em vários pontos do Brasil por pessoas que colocam frutas no quintal para eles comerem (V. Boere, comunicação pessoal). No Jardim Botânico de Brasília existem grupos de sagüis que são alimentados por alguns moradores do bairro Lago Sul principalmente no período das férias (observação pessoal). No Amazonas alguns hóspedes de hotéis de selva tiveram seus quartos invadidos por macacos em busca de alimento enquanto eles estavam fora passeando pela região (J. Stemler, comunicação pessoal).



Figura 5. Interação de alimentação artificial com macacos (sagüis - Callithrix penicillata) no Brasil. Foto: Danilo Gustavo Oliveira 


\subsection{2 - Outros mamíferos}

Talvez o caso mais famoso de interação entre turistas e animais no Brasil é o que ocorre com os quatis no Parque Nacional do Iguaçu. Os quatis são animais que apresentam uma olfação bastante desenvolvida (o próprio nome científico Nasua nasua, que significa nariz nariz, já diz isso) e freqüentemente atacam turistas com pertences cheirando a comida. Um saco plástico que carregou, 2 horas antes, sanduíches para o almoço de um grupo de visitantes foi a razão para turistas serem cercados e atacados pelos quatis que acabaram conseguindo o saco e o rasgando todo, provavelmente engolindo algumas partes (observação pessoal). De acordo com Pereira-Oliveira et al (2004) a dieta desse grupo é diferente daquela encontrada em animais não aprovisionados estudados em outras áreas, com uma quantidade muito menor de vertebrados e a presença principal de insetos e sementes nas fezes coletadas. Essa diferença na dieta, com a inclusão de itens artificiais, está fazendo com que alguns animais fiquem visualmente obesos (Pereira-Oliveira et al, 2004).

Outros casos existem no Pantanal, onde turistas tentam se aproximar demais de animais selvagens para conseguir uma melhor fotografia e acabam estressando e espantando veado-campeiro, tamanduá-bandeira, lontras, ariranhas e alguns canídeos e felinos pequenos (observação pessoal). Casos de animais que se afastam da aproximação exagerada de grupos de turistas existem em todo o Brasil, mas por causa da falta de documentação e publicação desses dados pouco se sabe sobre esses impactos. 


\section{2 - TURISMO DE OBSERVAÇÃO DA VIDA AQUÁTICA}

O Brasil se destaca no turismo de observação de vida aquática por ter uma grande quantidade de corpos d'água, mananciais e praias habitadas por uma grande diversidade de formas de vida. Os turismos de observação de cetáceos, de mergulho e de ambientes recifais compõem essa forma de interação com a natureza.

\subsection{1 - Turismo de Observação de Cetáceos}

Provavelmente o segmento do turismo de observação de cetáceos, também chamado de observação de baleias, é no Brasil o que está melhor organizado em termos de pesquisa científica (Rocha \& Ott, 2003; Rocha \& Andriollo, 2005)e infra-estrutura para o turismo. No Brasil existem algumas instituições de pesquisa que visam proteger os animais marinhos locais, conscientizando a população visitante e residente e disciplinando o turismo. A lista inclui instituições como instituto baleia jubarte e projetos Tamar, golfinho rotador, baleia-franca, boto-cinza, peixe-boi-marinho dentre outras que ajudam a tornar o processo de desenvolvimento desse tipo de turismo mais harmônico e sustentável.

Dada a existência de vários institutos de pesquisa conseguimos maior número de respostas aos questionários enviados por correio eletrônico. O Projeto Golfinho Rotador, o Instituto Baleia Jubarte e o Projeto Boto Cinza de Cananéia-SP responderam à pesquisa enviada. Estes dados encontram-se discutidos nos parágrafos seguintes.

Segundo José Martins da Silva Júnior (comunicação pessoal), do Projeto Golfinho Rotador em Fernando de Noronha-PE, a atividade turística não gerou até o momento casos de acidentes com lesão nos turistas e nem nos golfinhos (Stenella longirostris). Essa interação mais pacífica é mantida por um condutor de visitantes ou um membro do centro golfinho rotador que acompanha todas as embarcações e visitas ao mirante e impede os 
turistas de alimentarem os animais. Apesar do impacto turístico não ser alto para a população de golfinhos residentes, visto que a probabilidade de avistamento e a taxa de ocupação não terem diminuído ao longo dos anos, a pressão sobre o comportamento individual molesta os animais. O aumento do fluxo turístico de embarcações no arquipélago tem aumentado o gasto energético dos golfinhos e diminuído o tempo disponível para descanso e reprodução. Isso resulta em estresse nos animais e diminuição da taxa reprodutiva da população.

O Instituto Baleia Jubarte possui associação com apenas uma operadora de turismo para conduzir as visitas com membros do projeto. Os visitantes não podem alimentar os animais e nenhum turista ou animal saiu machucado ou doente em decorrência da interação. O desenvolvimento do turismo nessa região tem sido lento, talvez devido à falta de infraestrutura local ou por causa do auge da temporada de baleias não coincidir com o período de férias escolares (Morete et al, 2003). Isso tem um lado positivo, pois esse desenvolvimento lento permite aos pesquisadores estudarem a espécie e pensar na melhor forma de gerir a área antes da atividade se tornar intensa. De acordo com a pesquisadora do instituto Kátia Groch (comunicação pessoal) o programa tem gerado renda para a população local e para o município, além de ser importante na luta contra a volta da caça às baleias.

A região de Cananéia apresenta alguns relatos trágicos de turistas com golfinhos, inclusive o que deve ser o caso mais extremo de acidente com golfinhos solitários sociáveis, em que um garoto enfiou um palito de sorvete no orifício respiratório do animal e o cetáceo respondeu agressivamente levando o menino à morte (WDCS, 2005). Outros casos como atropelamentos de botos (Sotalia guianensis) com embarcações, principalmente jet-skis, causaram hemorragias nos animais e até mesmo os mataram (Gica Filla, 
comunicação pessoal). O Projeto Boto-Cinza hoje possui estagiários durante todo o verão nas embarcações e praias da região e dando palestras gratuitamente de educação ambiental, de biologia dos animais e características físicas locais. Os animais têm seu comportamento alterado devido ao alto fluxo turístico, porém maiores informações só estarão disponíveis quando do término do mestrado de Gica Filla (comunicação pessoal).

Em regiões com alto fluxo de embarcações turísticas de observação de baleias e golfinhos os animais visados mudam o seu comportamento em resposta à aproximação de embarcações. Esse é o caso da praia de Pipa-RN em que a aproximação muito próxima (menos de 100m) de embarcações causa um aumento no tempo de submersão dos golfinhos e diminuição no espaçamento individual dentro do grupo (Valle \& Mello, 2006). As operadoras de passeios de barco em Pipa permitem aproximação a menos de 20 m e experiências de nado com os golfinhos (observação pessoal), apesar de ser contra a lei federal (IBAMA, 1996).

No litoral norte da Bahia as baleias jubarte não apresentaram diferenças significativas de comportamento entre dois tipos de embarcações: turismo e pesquisa (Simões, 2005). Esse fato indica que os cruzeiros de turismo estão causando pouco impacto, já que é similar à perturbação causada pelos pesquisadores, ou então os dois causam impactos similares.

O turismo de observação de cetáceos é o segmento turístico que mais cresce no mundo todo (Hoyt, 2001). Esse crescimento no Brasil, apesar de rápido, tem sido relativamente bem acompanhado e estudado por instituições de pesquisa ao longo de todo o litoral. Apesar de trabalhos relatando mudanças comportamentais de curto-prazo (Valle \& Mello, 2006) e relatos de acidentes desastrosos ocorridos (golfinho matou uma criança e foi 
morto em Cananéia) nenhum caso foi encontrado de diminuição da população animal local por causa do turismo. Isso sugere um nível aceitável de utilização do recurso.

\subsection{2 - Turismo de Mergulho e de Ambientes Recifais}

A prática de mergulho é utilizada para entrar em contato mais íntimo com a vida animal subaquática, tanto em ambientes recifais marinhos quanto em formações fluviais e lacustres. O mergulho pode ser entendido como a tentativa mais genuína do homem de compreender como se organiza e existe a vida em meio aquático. Talvez por essa predisposição ao conhecimento os praticantes dessa atividade são mais abertos às práticas de educação e conscientização ambiental.

Tendo essa perspectiva, a área no Brasil que é considerada modelo na realização de um turismo responsável e com práticas ambientais de mínimo impacto é o município de Bonito-MS. Este município se desenvolveu de uma região predominantemente ligada à agricultura para um pólo de ecoturismo regional utilizando a beleza dos seus rios de água cristalina. Para garantir uma melhor gestão dos seus recursos, Bonito implementou um sistema integrado entre as ações públicas e privadas baseado em um voucher único, o que facilita o controle e administração, e um forte conselho municipal de turismo (Camargo \& Jóia, 2004). Além disso, foi implementado um programa de treinamento do visitante para que ele não cause grandes perturbações ao ambiente, assim como medidas de controle (flutuadores aquáticos, redução ou proibição de oferta de milho aos peixes etc) (Sabino \& Andrade, 2003).

Mesmo sendo conhecido por suas práticas ambientais sustentáveis, Bonito ainda apresenta alguns sérios problemas com os impactos ambientais do turismo. O tamanho e a riqueza da comunidade de peixes vêm diminuindo desde 2002, devido provavelmente à 
diminuição da oferta de alimento causada pela movimentação de remos e mergulhadores no local (Sabino \& Andrade, 2003). Algumas espécies chegaram a desaparecer dos monitoramentos trimestrais. Outro problema é a oferta de alimento no local por parte de visitantes e guias turísticos para enriquecer a experiência turística, o que vem causando obesidade nas piraputangas (Brycon hilarii), uma espécie muito visada pelos operadores de passeios turísticos (Sabino et al, 2004).

No litoral ocorre uma mistura dos turistas de mergulho com os adeptos do turismo de mar e sol, que ocorre geralmente em massa. Esses turistas de massa optam por fazer um mergulho como uma de várias atrações possíveis e não como forma de conhecimento e interação com a vida aquática. Portanto, o turismo em ambientes recifais tende a se distanciar da proposta de ecoturismo como forma de conservar a natureza. Um exemplo no litoral nordestino é Porto de Galinhas-PE, que não possui programa de educação ou de redução de impactos ambientais e os turistas oferecem comida aos peixes em abundância para enriquecer a experiência (observação pessoal).

Os principais impactos da atividade turística em recifes se devem à prática de mergulho, ancoragem de barcos e pisoteio (Mello et al, 2005). Os impactos causados pelos mergulhadores estão relacionados à falta de orientação e à inabilidade de se controlar dentro d'água, ao toque com o joelho, mãos ou pés em regiões do substrato, tentativa de chegar perto, fotografar e o contato ou fornecimento de alimentos a animais marinhos (The Coral Reef Alliance, 2007). A ancoragem prejudica os corais por destruir porções de rochas e de animais marinhos com o peso da âncora e a movimentação das correntes no substrato (CRC Reef Research Centre, 2003 apud Mello et al,2005). Esses impactos podem causar diminuição da beleza cênica dos recifes e simplificação da comunidade biológica existente no local (Tratalos \& Austin, 2001; Hawkins \& Roberts, 1993). 
O Brasil possui a maior riqueza de peixes de águas doces do mundo (Sabino \& Andrade, 2003) e uma grande extensão de costa com formações recifais com muita diversidade biológica. Essa indústria, apesar de bem difundida, pode crescer ainda utilizando um público mais especializado nessa atividade e não turistas generalistas de massa. Mergulhadores conscientes podem auxiliar bastante na conservação dos recursos naturais locais e incentivar práticas mais harmoniosas.

\section{3 - OBSERVAÇÃO DE AVES}

A atividade de observação de aves atrai um público bastante específico que percorre o mundo procurando as espécies mais raras e colecionando observações. Devido a essa característica, a procura por espécies incomuns, a atividade possui grande potencial para se desenvolver no Brasil, que possui alto número de espécies endêmicas. ${ }^{13}$. (Venturini et al, 2005; Braz et al, 2003; Silveira et al, 2003). Porém, é intrigante observar que essa prática não se popularizou no nosso país e parece não cativar o público local.

Essa atividade turística é relativamente cara para se praticar. A compra de binóculos, de máquinas fotográficas com zoom, de gravadores de som e outros produtos eletrônicos de alta tecnologia comum na atividade parece espantar os menos favorecidos economicamente e tornar essa prática elitizada. Outro fator que se soma a isso é o fato de os praticantes terem alto conhecimento sobre as diferentes espécies de aves e o habitat que elas ocupam, tornando necessário um certo nível de dedicação e estudo para se apreciar a atividade. Talvez o baixo nível educacional e financeiro da maioria da população brasileira

\footnotetext{
${ }^{13}$ Espécies endêmicas são aquelas que só ocorrem em um determinado local. Por exemplo, as espécies endêmicas ao Brasil só existem nesse país e endêmicas à Mata Atlântica só ocorrem nesse ecossistema.
} 
não favoreça a prática desse hobby em nível local, somente voltado para o público internacional.

No Brasil ocorre principalmente no Pantanal e na Amazônia esse tipo de atividade voltado especialmente para o turismo internacional. Um exemplo disso é o projeto arara azul que organiza grupos guiados para conhecer as atividades do projeto e os animais pesquisados nessa região do Pantanal e respondeu ao questionário eletrônico. Tal projeto apresenta sites em inglês na internet visando divulgar a atividade a pessoas de outros países ${ }^{14}$. Nesse projeto, turistas não podem encostar ou alimentar os animais, apenas os pesquisadores são permitidos, e a observação se dá apenas à distância. Devido a essa distância mantida os riscos para humanos e animais diminuem e os animais não mudam visivelmente seu comportamento, é o que afirma a pesquisadora do projeto Eveline Guedes (comunicação pessoal).

Outro local também freqüentado por observadores de aves é uma colônia de aves aquáticas no município de Barão de Melgaço-MT também no Pantanal. Nesse local são organizados passeios de barco para a observação da colônia e vários atores se beneficiam social e economicamente da atividade (Bouton \& Frederick, 2003).

O Brasil deveria incentivar o desenvolvimento dessa atividade de forma mais ampla, já que ela é considerada uma das atividades turísticas mais sustentáveis considerando todos os níveis (Sekercioglu, 2002) e tem um grande potencial para se desenvolver devido à alta diversidade de aves existentes. Por causa do dinheiro e do respeito ao local trazido pelos turistas há um maior desenvolvimento econômico e social e também um incentivo à manutenção do meio ambiente e da cultura local. Apesar de utilizar algumas práticas que

\footnotetext{
${ }^{14}$. ver: http://www.projetoararaazul.org.br/sitearara_programapantanal.htm.
} 
modificam o comportamento dos animais visados (como o uso de playbacks) a atividade proporciona um baixo impacto na população animal (Sekercioglu, 2002).

\section{4 - CAÇA E PESCA ESPORTIVA}

Essas são as formas tradicionais de turismo de vida selvagem consideradas consumidoras. A caça esportiva não é uma atividade de grande expressão no Brasil, mas o mesmo não pode ser dito da pesca, que ocorre nos principais rios e praias do país.

A pesca é considerada pela maioria da população como uma atividade não nociva e de relaxamento de forma harmoniosa. Acontece que o impacto que causa ao animal é muito grande e pode levá-lo à morte quando a luta é intensa (Balon, 2000).

Outro impacto que pode surgir ao nível da comunidade biológica existente é a introdução de espécies exóticas no rio para aumentar a eficiência de captura dos praticantes dessa atividade. No Canadá, onde essa prática é bastante popularizada, foram introduzidas espécies exóticas de Salmão do Pacífico nos Grandes Lagos para dar mais vigor à prática (Balon, 2000). No Brasil, a introdução de tucunaré em vários rios brasileiros causou grandes impactos nas suas faunas, reduzindo em muitos locais a diversidade biológica existente (Tait, 2005). No Parque Estadual do Rio Doce-MG, a comparação entre dois rios com e sem a introdução de tucunaré mostrou redução nos índices de densidade, riqueza, eqüitabilidade e diversidade com essa espécie exótica ao meio (Cota et al, 2002)

Outra problema também presente é o fato de pescadores utilizarem outros animais para encontrar os peixes e perturbarem mais de uma população no local. Esse é um caso que ocorre no município de Barão de Melgaço na região do Pantanal, onde uma colônia de aves aquáticas é constantemente perturbada por pescadores competindo pelos mesmos 
peixes (Bouton \& Frederick, 2003). Essa intervenção tem causado séria perturbação para a colônia e prejudicando um recurso de importante valor turístico para a região.

A pesca e a caça esportiva, apesar de estressante ou fatal para os animais e, em muitos pontos, antiética, pode ser um fator de desenvolvimento sustentável (econômica, social e ambientalmente) e de garantia da manutenção das comunidades animais no local. Reiss (2003) discute casos de quatro localidades na região amazônica em que a implementação de um programa de pesca de somente captura e soltura trouxe renda para a população local e fez a comunidade de peixes no local crescer e aumentar de tamanho corporal. Porém o mesmo autor discute a importância de se utilizar as técnicas mais eficientes para a redução de danos no animal (Reiss et al, 2003).

A caça esportiva também pode ser implantada de forma sustentável gerando até mais renda, respeito à cultura local e conservação ambiental do que a maioria das demais práticas. É o que defende Baker (1997) sobre a prática em parques africanos, se corretamente aplicada e gerida pelos responsáveis. Porém essa atividade não apresenta grande potencial para se desenvolver no Brasil porque a fauna brasileira não apresenta grandes mamíferos terrestres em abundância e os que existem estão, na sua maioria, seriamente ameaçados de extinção.

\section{5 - SUGESTÕES}

O turismo de vida selvagem no Brasil possui grande potencial para se desenvolver devido à grande diversidade de animais e a presença de espécies únicas e de beleza rara. No entanto, se o desenvolvimento dessa forma de turismo ocorrer descontroladamente o impacto sobre o animal visado será tão grande que esse processo rapidamente entrará em 
colapso. Para evitar isso muitos autores deram sugestões sobre como agir de forma a minimizar impactos do turismo em vida selvagem.

Uma característica do turismo de vida selvagem é a busca por animais grandes, mortais, próximos e em grandes números (Newlands, 1997). O uso de um binóculo cria a ilusão no praticante de que os animais estão próximos e são grandes, dessa forma mantendo os turistas naturalmente mais afastados. O uso de outras formas de lentes de aumento como lunetas e máquinas fotográficas ou filmadoras com zoom também diminui a necessidade de grande aproximação real dos animais. Áreas naturais protegidas por lei brasileira poderiam só permitir a entrada de pessoas com binóculos, havendo na entrada da unidade uma área para aluguel do equipamento. Outra alternativa seria os guias turísticos que realizam passeios visando encontrar animais selvagens, carregar binóculos suficientes para todos os participantes do passeio e educar os turistas a observar à distância.

A maioria dos cuidados com relação a minimizar impactos no comportamentos dos animais se refere a não deixar que o animal perceba que os turistas estão presentes. Essa atitude envolve ser silencioso, paciente e com um cheiro não facilmente perceptível (sem perfumes fortes e alimentos cheirosos) (Amodeo, 2004). Essas recomendações também deveriam ser transmitidas aos visitantes em passeios em áreas naturais brasileiras através de palestras ou do próprio guia, assim como a realização de passeios mais longos para se permitir que o visitante procure o animal com calma e com menos pressão nele.

Para que ocorra uma correta realização da atividade e que seja gerida mais facilmente é necessário um adequado treinamento dos condutores de visitantes. Um condutor bem treinado pode servir como um agente de conservação ambiental, fiscalização da atividade, promotor de educação ambiental e entreter o passeio. Por outro lado um guia não capacitado pode ser fonte de maior perturbação ambiental e desarmonia na realização 
da atividade recreativa. Guias precisam trabalhar em harmonia com a administração da unidade para facilitar o processo de gestão.

Por fim, acredito que duas atividades turísticas são bastante promissoras no Brasil e têm sido negligenciadas ao longo dos tempos. A atividade de observação de aves pela grande diversidade de aves presentes no território nacional e a grande renda movimentada por praticantes no mundo inteiro tem potencial para fazer um novo pólo de desenvolvimento econômico, social e ambiental. Também a atividade de pesca esportiva “pega e solta” pode ser praticada com muita facilidade e, se bem planejada e implementada, impacta pouco as populações animais procuradas e gera renda para a comunidade local. 


\section{CONSIDERAÇÕES FINAIS}

Podemos resumir todas as sugestões apresentadas nessa monografia no seguinte: passar por uma área natural e observar os animais de forma que estes não percebam a sua presença. Estes cuidados incluem basicamente diminuir o barulho (evitar playbacks e conversas altas), diminuir a quantidade de pessoas em cada grupo (respeitar a capacidade de carga do local), evitar cheiros fortes e atrativos (perfumes e alimentos muito cheirosos) e manter distância considerável do animal (uso de binóculos e outras lentes de aumento e estimular a educação ambiental). Também é importante ressaltar que não é aconselhável alimentar animais selvagens a menos que incentivado por especialistas e que não se deve se aproximar doente de animais em áreas naturais.

A capacitação profissional de guias pode também auxiliar bastante na atitude mais ambientalmente correta de visitantes durantes passeios e trilhas guiadas. Atividades turísticas como observação de aves e prática de pesca e solta podem ainda crescer muito no Brasil e, se feitos de forma responsável, causando grandes benefícios econômicos e sociais com um impacto ambiental reduzido.

Durante a escrita dessa monografia muitas dificuldades atrapalharam o avanço do trabalho. O acervo de revistas de periódicos das bibliotecas e órgãos de incentivo à pesquisa brasileira que tive acesso não disponibilizavam trabalhos de mais de 15 anos de publicados e muitos trabalhos eram de antes de 1990. Outro problema foi a falta de acesso a monografias e dissertações feitas e não publicadas que só podem ser consultadas nas bibliotecas de origem do trabalho. Critério mais técnico que atrapalhou alguns fatos foi a falta de delimitação conceitual de alguns termos como turismo de vida selvagem (não existe essa segmentação pelo governo brasileiro) e turismo de safári. 
Enfim, a área de impactos do turismo em vida selvagem no Brasil ainda carece de muitos estudos e pesquisas. Na maior parte das áreas ainda não existem estudos sistemáticos sendo realizados (exceção no turismo de observação de cetáceos) ou a pesquisa ganharia muito com a compreensão multidisciplinar. Muito trabalho ainda existe a ser feito para a compreensão da melhor forma de desenvolvimento sustentável do turismo brasileiro. 


\section{COMUNICAÇÕES PESSOAIS}

Dr. V. Boere, Universidade de Brasília, Brasília, DF.

R. Dias, Centro de Excelência em Turismo, Brasília, DF.

G. Filla, Projeto Boto Cinza, Instituto de Pesquisas Cananéia, Cananéia, SP

K. Groch, Instituto Baleia Jubarte, Caravelas, BA

E. Guedes, Projeto Arara Azul, Cuiabá, MT.

L. Pangela, estudante de especialização, Centro de Excelência em Turismo, Brasília, DF

J. M. Silva-Júnior, Projeto Golfinho Rotador, Fernando de Noronha, PE

A. J. Stemler, estudante de especialização, Universidade Estadual de Goiás, Formosa, GO

\section{REFERÊNCIAS BIBLIOGRÁFICAS}

Amo, L.; López, P. \& Martin, J. (2006).Nature-based tourism as a form of predation risk affects body condition and health state of Podarcis muralis lizards. Biological Conservation. 131, 402-409

Associação Mico-Leão-Dourado. Histórico. Extraído da url: http://www.micoleao.org.br/template.php?pagina=/ptg/associacao/historico.php. Acessado em 29/01/2007.

Au, W. W. L. \& Green, M. (2000). Acoustic interaction of humpback whales and whalewatching boats. Marine Environmental Research, 49, 469-481.

Amodeo, C. (2004). Close encounters of the wild kind. Geographical. 79(2): 89-94.

Baker, J. E. (1997). Trophy Hunting as a Sustainable Use of Wildlife Resources in Southern and Eastern Africa. Journal of Sustainable Tourism. 5(4), 306-321. 
Baldellou, M \& Adan, A. (1997). Time, gender, and seasonality in vervet activity: a chronobiological approach. Primates, 38(1): 31-43

Balon, E. K. (2000). Defending fishes against recreational fishing: an old problem to be solved in the new millennium. Environmental Biology of Fishes. 57, 1-8.

Baskin, Y. (1994) There’s a new wildlife policy in Kenya: Use it or lose it. Science 265, 733-4.

Bejder, L. and Samuels, A. 2003. Evaluating the effects of nature-based tourism on cetaceans. In: Gales, N.; Hindell, M.; Kirkwood, R. (eds.) pp. 229-256. Marine Mammals: Fisheries, Tourism and Management Issues. CSIRO Publishing. 480 pp.

Blom, A.; Cipolletta, C.; Brunsting, A. M. H. \& Prins, H. H. T. (2003). Behavioral Responses of Gorillas to Habituation in the Dzanga-Ndoki National Park, Central African Republic. International Journal of Primatology. 25(1), 179-196.

Burger, J. \& Gochfeld, M. (1998). Effects of ecotourists on bird behaviour at Loxahatchee National Wildlife Refuge, Florida. Environmental Conservation. 25(1), 13-21.

Burns, G. L. \& Howard, P. (2003). When wildlife tourism goes wrong: a case study of stakeholder and management issues regarding Dingoes on Fraser Island, Australia. Tourism Management. 24, 699-712.

Bouton, S. N. \& Frederick, P. C. (2003). Stakeholders' Perceptions of a Wading Bird Colony as a Community Resource in the Brazilian Pantanal. Conservation Biology. 17(1), 297-306.

Braz, V. S.; Abreu, T. L. S.;Lopes, L. E.;Leite, L. O.; França, F. G. R.; Vasconcellos, M. M. \& Balbino, S. F. (2003). Brazilian Merganser Mergus octosetaceus discovered in Jalapão State Park, Tocantins, Brazil. Catinga. 20,68-71. 
Camargo, E. I.; Joia, P. R. (2004). O gerenciamento do turismo em Bonito, MS. Anais do IV Simpósio sobre recursos naturais e sócio-econômicos do Pantanal. Corumbá. MS.

Cassini, M. H.; Szteren, D. \& Fernández-Juricic, E. (2004). Fence effects on the behavioural responses of South American fur seals to tourist approaches. Japan Ethological Society and Springer, 22, 127-133.

Chacra, G. (2005). África do Sul: Rota costeira extrapola lado safári. Extraído da url: http://www1.folha.uol.com.br/folha/turismo/noticias/ult338u5044.shtml. Acessado em 29/01/2007.

Colombini, F. R. X.; Scoss, L. M. \& Zappes, C. A.(2004). Relação entre Turistas e Padrões Comportamentais de Cebus nigritus (Primates; Cebidae) no Parque Estadual do Rio Doce, MG. Anais do XXII Encontro Anual de Etologia. Campo Grande. MS

Constantine, R. (1999). Effects of tourism on marine mammals in New Zealand. Science for Conservation Series, 106. Department of Conservation, Wellington, New Zealand, pp: 60.

Cota, L. R.; Callisto, M. \& Ferreira(2002). Efeito da introdução de tucunaré e piranha sobre a comunidade de macroinvertebrados bentônicos em duas lagoas (PERD-UFMG). In: XI Semana de Iniciação Cientifica da UFMG. Minas Gerais.

Coltman, D. W.; O’Donoghue, P; Jorgenson, G.T.; Hogg, J.T.; Strobeck, C. \& FestaBlanchett, M. (2000). Undesirable evolutionary consequences of trophy hunting. Nature. 426(11), 655-658.

Davis, D. \& Tisdel, C. (1995).Recreational scuba-diving and carrying capacity in marine protected areas. Ocean \& Coastal Management, 26 (1), 19-40. 
De Freitas, C. H. \& Dias, R. C. (2004). Estudo dos atropelamentos fatais de mamíferos silvestres no Triângulo Mineiro e Nordeste do Estado de São Paulo. Anais do XXV Congresso Brasileiro de Zoologia. Universidade de Brasília, Brasília, DF.

Eckhardt, G. (2000). The effects of ecotourism on polar bear behaviour. Dissertação de mestrado, universidade da Flórida Central, Orlando, Florida

EMBRATUR (2006). Segmentação do turismo: marcos conceituais. 56p.

Ferreira, R. L. Z. (2005). Efeito da visitação pública sobre o comportamento de Cebus nigritus (primates; cebidae) no Parque Estadual do Rio Doce, MG. Monografia de conclusão de curso de bacharelado em Biologia. Universidade Vale do Rio Doce, MG.

Furtado, M. M.; Kashivakura, C. K.; Ferro, C.; Astete, S. H.; Suero, D.; Tôrres, N. M.; Jácomo, A. T. A. \& Silveira, L. (2004). Impacto do atropelamento de mamíferos silvestres na região do Parque Nacional das Emas. Anais do XXV Congresso Brasileiro de Zoologia. Universidade de Brasília, Brasília, DF.

Futuyma, D. J. (1986). Biologia Evolutiva. (M. de Vivo \& F.M. Sene, trads.). Ribeirão Preto: FUNPEC Editora. Segunda edição.

Grossberg, R.; Treves, A. \& Naughton-Treves, L. (2003). The incidental ecotourist: measuring visitor impacts on endangered howler monkeys at a Belizean archaeological site. Environmental Conservation. 30 (1), 40-51.

Hawkins, J. P. \& Roberts, C. M. (1993). Effects of recreational scuba diving on coral reefs: trampling on reef-flat communities. The Journal of Applied Ecology, 30 (1), 25-30.

Hoyt, E. (2001). Whale watching 2001: worldwide tourism numbers, expenditures, and expanding socioeconomic benefits. A special report from the International Fund for Animal Welfare. Yarmouth Port, MA, USA. 
IBAMA. Disponível no site: http://www.ibama.gov.br/cpb/index.php?id_menu=104. Acesso em 21/03/2007.

Instituto Brasileiro do Meio Ambiente e Recursos Naturais Renováveis - IBAMA (1996).

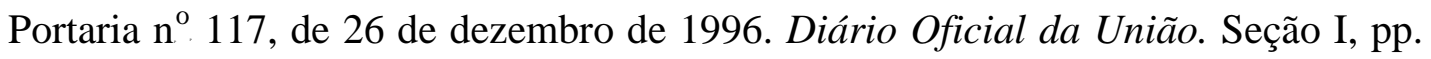
028786

Johnson, D. M. \& Lavigne, D. M. (1999). Mass tourism and the mediterranean monk seal. The Monachus Guardian, 2(2).

Lemelin, R.H. \& Smale, B. (2005). Wildlife viewers archetypes: are they all ecotourists. Paper presented at the $11^{\text {th }}$ Canadian Congress on Leisure Research.

Lusseau, D (2003). Effects of tours boats on the behaviour of bottlenose dolphins: using Markov Chains to model anthropogenic impacts. Conservation Biology, 17 (6), 1785-1793.

Lusseau, D. (2004). The hidden cost of tourism: detecting long-term effects of tourism using behavioral information. Ecology and Society, 9(1): 2.

Martins, L. B. R. (2005). Interações e conflitos entre humanos e macacos-prego (Cebus apella) no parque da Criança em Anapólis-GO. Dissertação de mestrado. Universidade Católica de Goiás, Brasil.

McClanahan, T. R. (1999). Is there a future for coral reef parks in poor tropical countries? Coral Reefs, 18, 321-325.

Mello, R. S.; Crispim, M. C. \& Lima, E. R. V. (2005). Turismo em ambientes recifais: em busca da transição para a sustentabilidade. Caderno virtual de turismo. 5(4), 34-42.

Mendes, F. D. C. (2006). Behavioral flexibility and conflict between humans and urban cappuchin monkeys in Goiânia, Goiás. Anais do XXIV Encontro Anual de Etologia. Brasília, Distrito Federal, Brasil. 
Mendes, F. D. C.; Guimarães, Z. F. S.; Portela, R. C.; Rocha, S. A. A. \& Martins, L. B. R. (2004). Agressividade de macacos-prego a humanos em áreas antropizadas: possíveis causas e conseqüências. Anais do XXII Encontro Anual de Etologia. Campo Grande. MS.

Mendes, F. D. C.; Rocha, S. A. A.; Balestra, R.; Guimarães, Z. F. S. \& Portela, R. C. (2005). Padrões comportamentais de Cebus apella libidinosus em fragmentos de matas urbanas: adaptabilidade, problemas de convivência e manejo. Anais da Sociedade Brasileira de Primatologia. Porto Alegre. RS.

Nellemann, C.; Jordhoy, P.; Stoen, O. G. \& Strand, O. (2000). Cumulative Impacts of Tourist Resorts on Wild Reindeer (Rangifer tarandus tarandus) during Winter. Arctic. 53(1), 9-17.

Newlands, W. (1997). All creatures great, small and deadly. The Sunday Times, 19 january 1997.

O’Leary, R.\& Jones, D. N. (2006). The use of supplementary foods by Australian magpies Gymnorhina tibicen: Implications for wildlife feeding in suburban environments. Austral Ecology. 31, 208-216.

Orams, M. B. (2002). Feeding wildlife as a tourism attraction: a review of issues and impacts. Tourism Management. 23, 281-293.

Orams, M. B. (2000). Tourists getting close to whales, is it what whale-watching is all about?. Tourism Management, 21, 561-569.

Orams, M. B. (1995). Towards a more desirable form of ecotourism. Tourism Management. 16(1), 3-8. 
Pandey, P.; Shlim, D. R.; Cave, W. \& Springer, M. F. B. (). Risk of Possible Exposure to Rabies among Tourists and Foreign Residents in Nepal. Journal of Travel Medicine. 9(3), 127-131.

Pereira-Oliveira, P. C.; Candido-Jr., J. F. \& Damico, A. R. (2004). Análise preliminar da dieta de quatis Nasua nasua, (Carnivora:Procyonidae), do Parque Nacional do Iguaçu. Anais do XXV Congresso Brasileiro de Zoologia. Universidade de Brasília. Brasília, DF.

Pinha, P. S.; Waga, I.C.; Sabbatini, G.; Tavares, M.C.H. (2004). Comportamento alimentar de um grupo de macacos-prego Cebus apella (cebidae, primates) no Parque Nacional de Brasília. Anais do XXII Encontro Anual de Etologia. Campo Grande. MS.

Pough, F. H.; Janis, C. M. \& Heiser, J. B. (1999). Vertebrate life. New Jersey: Prentice Hall. $5^{\text {th }}$ Edition

Reiss, P. (2003). Observations of the Effects of Catch and Release Fishing in Amazonia. Disponível na url: http://www.acuteangling.com/Reference/C\&RMenu.html. Acessado em 15/03/2007.

Reiss, P.; Reiss, M. \& Reiss, J. (2003). Catch and Release Fishing Effectiveness and $\begin{array}{lll}\text { Mortality. } & \text { Disponível na }\end{array}$ http://www.acuteangling.com/Reference/C\&RMenu.html. Acessado em 15/03/2007

Richten, C.; Dawson, S. \& Sloothen, E. (2006). Impacts of commercial whale watching on male sperm whales at Kaikoura, New Zealand. Marine Mammal Science, 22(1):4663.

Rocha, S. A. A. (2003). Dieta e orçamento de atividades de Cebus apella área urbana. Dissertação de mestrado. Universidade Federal de Goiás. Brasil. 
Rocha, J. M. \& Ott, P. H. (2003). Brazil progress report on cetacean research, march 2002 to february 2003, with statistical data for the calendar year 2002 or season 2002/2003.

Rocha, J. M. \& Andriolo, A. (2005). Brazil. progress report on cetacean research, march 2004 to february 2005, with statistical data for the calendar season 2004/05

Roe, D.; Leader-Williams, N. \& Dalai-Claiton, B. (1997). TAKE ONLY PHOTOGRAPHS, LEAVE ONLY PHOOTPRINTS: the environmental impacts of wildlife tourism. IIED Wildlife and Development Series No 10.

Sabbatini, G.; Stammati, M.; Tavares, M. C. H., Giuliani, M. V. \& Visalberghi, E. (2005). Interactions between humans and capuchin monkeys (Cebus libidinosus) in the Parque Nacional de Brasília, Brazil. Applied Animal Behaviour Science. 97,272-283.

Sabino, J. \& Andrade, L. P. (2003). Uso e conservação da ictiofauna no ecoturismo da região de Bonito, Mato Grosso do Sul: o mito da sustentabilidade ecológica no rio Baía Bonita (aquário natural de Bonito). Biota Neotropica. 3,1-9.

Sabino, J.; Medina Jr., P. B. \& Andrade, L. P. (2005). Visitantes mal-comportados e piraputangas obesas: a pressão da visitação pública sobre Brycon hilarii no balneário municipal de Bonito, Mato Grosso do Sul, Brasil. III Encontro Nacional de Pesquisa e Iniciação Científica, 2005. Editora da UNIDERP, p. 321-332.

Saj, T.; Sicotte, P. \& Paterson, J. D. (1999). Influence of Human Food Consumption on the Time Budget of Vervets. Inernational Journal of Primatology. 20(6) 977-994.

Samuels A., Bejder, L., Constantine R., and Heinrich, S. 2003. Swimming with wild cetaceans in the Southern Hemisphere. In: Gales, N.; Hindell, M.; Kirkwood, R. (eds.) pp. 277-303. Marine Mammals: Fisheries, Tourism and Management Issues. CSIRO Publishing. 480 pp 
Sekercioglu, C. H. (2002). Impacts of birdwatching on human and avian communities. Environmental Conservation. 29(3), 282-289.

Silveira, L. F.; Olmos, F \& Long, A. J. (2003). Birds in atlantic forest fragments in northeast Brazil. Cotinga 20, 32-46

Simões, D. G. (2005). Comportamento das baleias jubarte (Megaptera novaeangliae) na região do Banco dos Abrolhos e Litoral Norte da Bahia. Dissertação de mestrado. Universidade de Brasília, Brasília - Brasil.

Tait, M. (2005). Impacto de espécies exóticas em água doce. ECO-21. 108. Disponível na url: http://www.eco21.com.br/textos/textos.asp?ID=1240\#.

THE CORAL REEF ALIANCE (2007). A practical guide to good practice managing environmental impacts in The Marine Recreation Sector. Disponível em: http:// www.coralreefalliance.org/parks/guidelines.html. Acesso em: 15 de março de 2007..

Tisdell, C. \& Wilson, C. (2002). Ecotourism for the survival of sea turtles and other wildlife. Biodiversity and Conservation. 11, 1521-1538.

Tratalos, J. A. \& Austin, T. J. (2001). Impacts of recreational SCUBA diving on coral communities of the Caribbean island of Grand Cayman. Biological Conservation, 102, 67-75.

Treeck, P. V. \& Schuhmacher, H. (1998). Mass Diving Tourism: A New Dimension Calls for New Management Approaches. Marine Pollution Bulletin, 37(8-12) 499-504.

Valle, A. L. \& Mello, F. C. C. (2006). Alterações comportamentais do golfinho Sotalia guianensis (Gervais, 1953) provocadas por embarcações. Biotemas. 19(1), 75-80.

Venturinni, A. C.; Paz, P. R. \& Kirwan, G. M. (2005). A new locality and records of Cherry-throated Tanager Nemosia rourei in Espírito Santo, south-east Brazil, with fresh natural history data for the species. Cotinga. 24, 60-70. 
Wallis, J. \& Rick Lee, D. (1999). Primate Conservation: the prevention of disease transmission. International Journal of Primatology. 20(6), 803-826.

WDCS (2005). Research and management of solitary, sociable odontocetes. Workshop workbook. San Diego, California, USA.

Whitman, K.; Starfield, A. M.; Quadling, H. S. \& Packer, C. (2004). Sustainable trophy hunting of African lions. Nature. 428(11), 175-178.

Wilson, C. \& Tisdell, C. (1999). Sea turtles as a non-consumptive tourism resource especially in Australia. Tourism Management. 22, 279-288

Zhao, Q. K. (1999). Responses to Seasonal Changes in Nutrient Quality and Patchiness of Food in a Multigroup Community of Tibetan Macaques at Mt. Emei. International Journal of Primatology. 20(4), 511-524. 